\title{
Evidence of mud volcanism due to the rapid compaction of Martian tsunami deposits in southeastern Acidalia Planitia, Mars
}

Ilaria Di Pietro ${ }^{\mathrm{a} 1}$, Antoine Séjournéb ${ }^{\mathrm{F}}$ François Costard $^{\mathrm{b}}$, Marta Ciążela ${ }^{\mathrm{c}}$ and J. Alexis Palmero Rodriguez ${ }^{d}$

a International Research School of Planetary Sciences (IRSPS), Dipartimento di Ingegneria e Geologia (INGEO), Università degli Studi Gabriele d'Annunzio, viale Pindaro 42, 65127 Pescara, Italy

b Géosciences Paris Sud (GEOPS), UMR 8148, Université Paris-Sud, CNRS, Rue du Belvédère, 91400 Orsay, France

c Space Research Centre, Polish Academy of Sciences (PAS), ul. Bartycka 18A, 00-716 Warsaw, Poland

d Planetary Science Institute (PSI), 1700 E Fort Lowell Rd \# 106, 85719 Tucson, Arizona, USA

${ }^{1}$ Dipartimento di Scienze Psicologiche, della Salute e del Territorio (DISPUTER), Università degli Studi Gabriele d'Annunzio, via dei Vestini 32, 66100 Chieti, Italy

Corresponding author:

\section{Ilaria Di Pietro}

Dipartimento di Scienze Psicologiche, della Salute e del Territorio (DISPUTER), Università degli Studi G. d'Annunzio, Via dei Vestini, 31 - 66100 Chieti, Italy

囷 ilaria.dipietro@unich.it

[] +393275863091 


\begin{abstract}
Thumbprint terrain was first recognized in Viking Orbiter data and described as sets of alternating continuous parallel ridges and depressions up to several tens of kilometres in length, with high and low albedo respectively. We performed a geomorphological analysis of these features using both Context Camera and High Resolution Imaging Science Experiment images, as well as topographic profiles based on Mars Orbiter Laser Altimeter data, with the aim to provide an origin for thumbprint terrain and constrain the geological evolution of southeastern Acidalia Planitia. The identification of runup lobate deposits, coupled with the putative presence of a Late Hesperian ocean in the northern lowlands, led to speculations that evidence of tsunamis may be present in the geologic record of the area. There are several hypotheses that have been proposed previously to explain the origin of thumbprint terrain and include ice-related, volcanicrelated, liquefaction and mud-volcanism driven processes. However, a tsunami-related origin provides a strong geological framework for the energy required for the associated lobes to flow uphill and leaving peripheral termination ridges as a result of viscosity. Numerical simulations indicate that - prior to their emplacement - the lobes sustained high velocities, thereby lending further support to the tsunami hypothesis and their origin from the Lomonosov crater impact. Wave interference patterns, formed during the propagation of the tsunamis over and around prominent topography, likely explain the thumbprint terrain spatial arrangement. The thumbprint terrain sedimentary cones are, herein, considered mud volcanoes related to a tsunami that occurred in southeastern Acidalia Planitia.
\end{abstract}




\section{Introduction}

The presence of a Hesperian ocean within the northern plains is one of the most debated issues of the Martian geology (Parker et al., 1989, 1993; Head et al., 1998, 1999; Clifford and Parker, 2001; Carr and Head, 2003; Tanaka et al., 2003, 2005). Its presence would imply that northern lowlands gathered a large quantity of water and sediments. Outflow channels, carved by large-scale floods (Carr, 1979), are commonly thought to have served as the primary supply of water which may have filled the northern lowlands in the Late Hesperian (Parker et al., 1989, 1993; Baker et al., 1991; Clifford and Parker, 2001; Tanaka et al., 2005). The ocean-hypothesis is supported by several flat surfaces that can be observed spanning thousands of kilometres and marking distinct units in the peripheral northern lowlands. These limits have been interpreted as paleo-shorelines (Parker et al., 1989, 1993; Clifford and Parker, 2001); for example, the Deuteronilus contact is characterized by very slight topographic variations $(-3792 \pm 236 \mathrm{~m})$, which are strikingly consistent with the paleo-shoreline hypothesis (Clifford and Parker, 2001; Carr and Head, 2003; Perron et al., 2007; Citron et al., 2018). On the other hand, some limits (i.e., Arabia contact) have topographic amplitudes of up to several kilometres that have initially been used against the ocean hypothesis (Head et al., 1998; Head et al., 1999; Carr and Head,2003). However, recent studies proposed that these limits represent deformed paleo-shorelines as the result of deformation related to true polar wander occurring before and during the massive Tharsis volcanic rise (Citron et al., 2018; Zuber, 2018) or after the formation of Tharsis region (Perron et al., 2007). Several studies have also showed that there could be a large reservoir of water/mud in the deepest portions of the Utopia basin during the Hesperian (Ivanov et al., 2014; Ivanov et al., 2015). This may potentially represent the remnant of a larger standing body of water, further supporting the presence of an ocean within the northern plains (Parker et al., 1989, 1993; Head et al., 1998, 1999; Clifford and Parker, 2001; Carr and Head, 2003; Tanaka et al., 2003, 2005). 


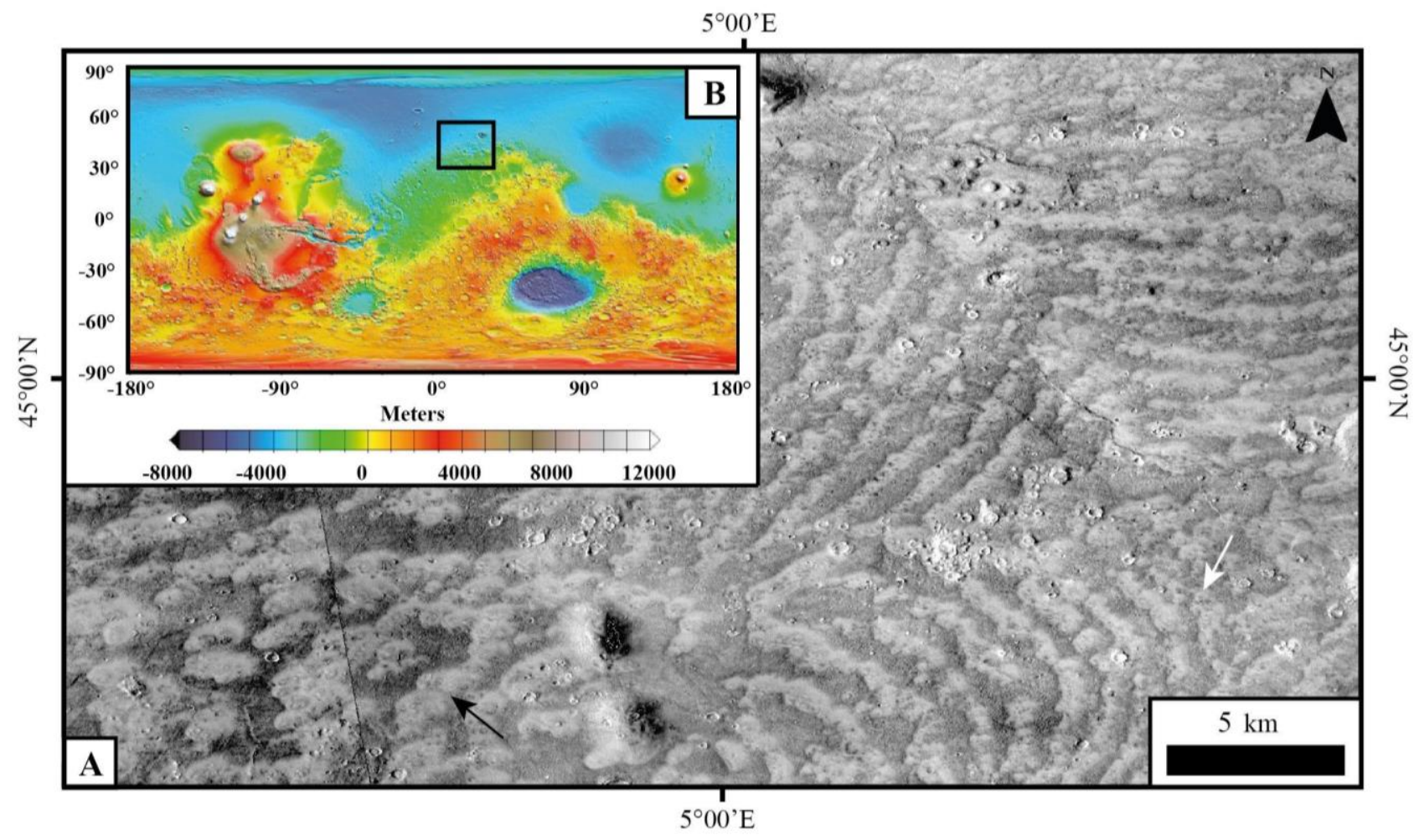

Figure 1. Thumbprint terrain in Acidalia Planitia. A) Thumbprint terrain at low resolution with a random arrangement (black arrow) on the left and an arcuate and parallel linear disposition (white arrow). B) Study area is marked by the black rectangle on the topographic map based on colorized Mars Orbiter Laser Altimeter data. Courtesy of NASA/JPL/Univ. of Arizona.

Thumbprint terrain (represented hereafter as TT) was previously recognized and described as continuous parallel and curvilinear ridges at regional scale (Fig. 1A - white arrow) on the basis of Viking Orbiter data (Lockwood et al., 1992). However, the wealth and increasing resolution of remotely sensed imagery showed it is comprised of both randomly (Fig. 1A - black arrow) and highly organized (Fig. 1A - white arrow) spatial patterns of individual pitted cones/small mounds that lie above lobate deposits. Thumbprint terrain overlies millions of square kilometres primarily in the northern plains between $30^{\circ} \mathrm{N}$ and $50^{\circ}$ (e.g., Acidalia Planitia, Utopia Planitia, etc...), although they also occur in a large area near the Martian equator (i.e., Isidis Planitia). Several hypotheses have been proposed for the origin of thumbprint terrain; with the majority of them involving the presence of ice/water. The individual cones were first interpreted as possible pseudo-craters formed by explosions associated with lava emplacement over wet ground (Frey and Jarosewich, 1982; Carr, 1986), cinder cones (Scott et al., 1995), pingos, ice-cored ridges (Lucchitta, 1981; Rossbacher and Judson, 1981), moraines (Lucchitta, 1981; Scott and Underwood, 1991; Kargel and Strom, 1992; Lockwood et al., 1992), or mounds formed by the disintegration of stagnant ice covers (Grizzaffi and Schultz, 1989). According to the most recent hypotheses, they are interpreted as mud 
volcanism-driven deposits (Tanaka et al., 2003; Salvatore and Christensen, 2014), liquefaction deposits (Skinner et al., 2008; Skinner and Fergason, 2010) or related to impact-generated tsunami lobate deposits (Rodriguez et al, 2016; Costard et al, 2017; Costard et al., 2019).

On Earth, the most common triggers of tsunamis are earthquakes, subaqueous landslides, and volcanic activity. Only on rare occasions meteorite crashes give rise to tsunamis, thus terrestrial impact-induced tsunami deposits are sparse (Paris et al., 2009; Bryant, 2001). Conversely, on Mars, impact-generated tsunamis seem to be a plausible trigger mechanism. The study area (SE Acidalia Planitia) is uniquely positioned in that numerical modelling and geologic investigation tie an asteroid impact (e.g., Lomonosov crater) to the generation of a tsunami wave (lijima et al., 2014; Rodriguez et al, 2016; Costard et al, 2017; Costard et al., 2019) that extended to the areas covered by thumbprint terrain. These numerical predictions, combined with geologic observations, demonstrate the importance of the study area and provides a convincing scenario for thumbprint terrain origin.

Here, we focused on thumbprint terrain (or TT), i.e. alignments of cones or mounds, in the southeastern Acidalia Planitia near the dichotomy $\left(43^{\circ}-53^{\circ} \mathrm{N} 0^{\circ}-22^{\circ} \mathrm{E}\right.$; Fig. 1B), in an effort to: (i) characterize their geographical distribution; (ii) describe their morphology and relationship with former/underlying topography around the dichotomy and (iii) discuss their origin considering evidences and regional geological context. We will refer to alignments of cones/mounds simply as "thumbprint terrain" or "TT"; while we will refer to both thumbprint terrain and underlying associated lobate deposits as "lobate TT unit". Although lobate deposits were not the focus of this study, it is useful to have a terminology that indicates both thumbprint terrain and underlying lobes when discussing the overall evolution of the area since target morphologies (TT) are closely related to lobate deposits in SE Acidalia Planitia.

\section{Stratigraphy}

The Vastitas Borealis Formation is the most widespread formation in the northern lowlands (Greeley and Guest, 1987; Tanaka and Scott, 1987). Many different hypotheses have been proposed to explain its origin, supporting either a sedimentary 
processes related to outflow channels (Kreslavsky and Head, 2002) or a volcanic process (Catling et al., 2012). Kreslavsky and Head (2002) asserted that a sedimentary section of the Vastitas Borealis Formation formed as a residue when water from the outflow channels settled, quickly froze, and then sublimated. However, recent studies suggested that portions of Vastitas Borealis Formation were emplaced and/or modified while still saturated with liquid water (McGill and Hills, 1992; Tuckwell et al., 2003; Buczkowski and Cooke, 2004; Cooke et al., 2011; McGowan, 2011; Buczkowski et al., 2012). Regional geologic mapping (Tanaka et al., 2005; Fig. 2) separated the Vastitas Borealis Formation into two distinct units: the interior (ABvi) and the marginal unit (ABvm). the ABvi unit is the more extensive of the two units and hosts most of the diagnostic Vastitas Borealis Formation morphological features (Salvatore and Christensen, 2014). Data from Mars Orbiter Laser Altimeter (MOLA) derived Digital Elevation Model (DEM) and several 100-m/pixel-resolution Thermal Emission Imaging System images (THEMIS) reveals that the ABvi unit is rougher and has a higher thermal inertia than the ABvm unit (Tanaka et al., 2005, and references therein). The ABvi unit also consists of relatively bumpy, plains-forming material (Tanaka et al., 2005) that covers most of the northern plains including Vastitas Borealis and Utopia, Acidalia, and northern Arcadia Planitiae. The outer parts of the ABvi unit include the lobate TT unit (Fig. 2), as well as random clusters of hills mostly $<1 \mathrm{~km}$ across (Frey and Jarosewich, 1982; Grizzaffi and Schultz, 1989; Scott et al., 1995). Approaching the edge of the unit, cones/mounds tend to decrease in quantity, occuring in random and small groups until their complete disappearance (Tanaka et al., 2005; Salvatore and Christensen, 2014). Conversely, the ABvm unit outcrops surround the ABvi in Utopia Planitia, along Arabia Terra, in southern Acidalia Planitia, north of Alba Patera, and in western Arcadia Planitia. At lower latitudes $\left(<25^{\circ} \mathrm{N}\right)$, it appears smoother, exhibits a higher albedo and lower thermal inertia than both the ABvi unit and surrounding materials in THEMIS daytime infrared images. This means that the ABvm unit is warmer, which may indicate a relatively fine-grained material compared to adjacent materials (Tanaka et al., 2005). Parts of the ABvm are buried by Amazonis and Elysium provinces materials. The ABvm unit also includes systems of fretted valleys that are a few kilometres wide and tens of kilometres long (Squyres, 1978; Carr, 1995; Tanaka et al., 2005). These features have no clear terrestrial analogues and they have previously been compared to glacial moraines and kame complexes (Lucchitta, 1981), glacial tunnel valley and esker features (Kargel et al., 1995), or soft-sediment deformation structures (Tanaka et al., 
2003). The Vastitas Borealis marginal and interior units generally have a poorly defined contact and post-emplacement material evolution. In addition, the southern limit of the collective outer margin of both Vastitas Borealis units is fairly constant in elevation ( $3900 \mathrm{~m} \pm 70 \mathrm{~m}$ ) and close to the mean elevation of the Deuteronilus contact (see section 1 ), hence it may indicate the presence of an ancient standing body of water (Parker et al., 1989, 1993; Head et al., 1999; Clifford and Parker, 2001; Carr and Head, 2003). In our study area, the Vastitas Borealis Formation approaches the Noachis Terra unit (Nn) (Fig. 2) and to a lesser extent the Deuteronilus Mensae 1 unit (HBd1; Mangold et al., 2002) (Fig. 2). The Noachis Terra unit is Middle to Late Noachian in age and represents mostly heavily cratered terrain (Tanaka et al., 2005). Most of the unit displays layering (Malin and Edgett, 2001), in MOC narrow-angle data. Elevation ranges between -2,000 and $-5,000 \mathrm{~m}$ within the northern plains across Orcus Patera and Acidalia Mensa (Tanaka et al., 2005).

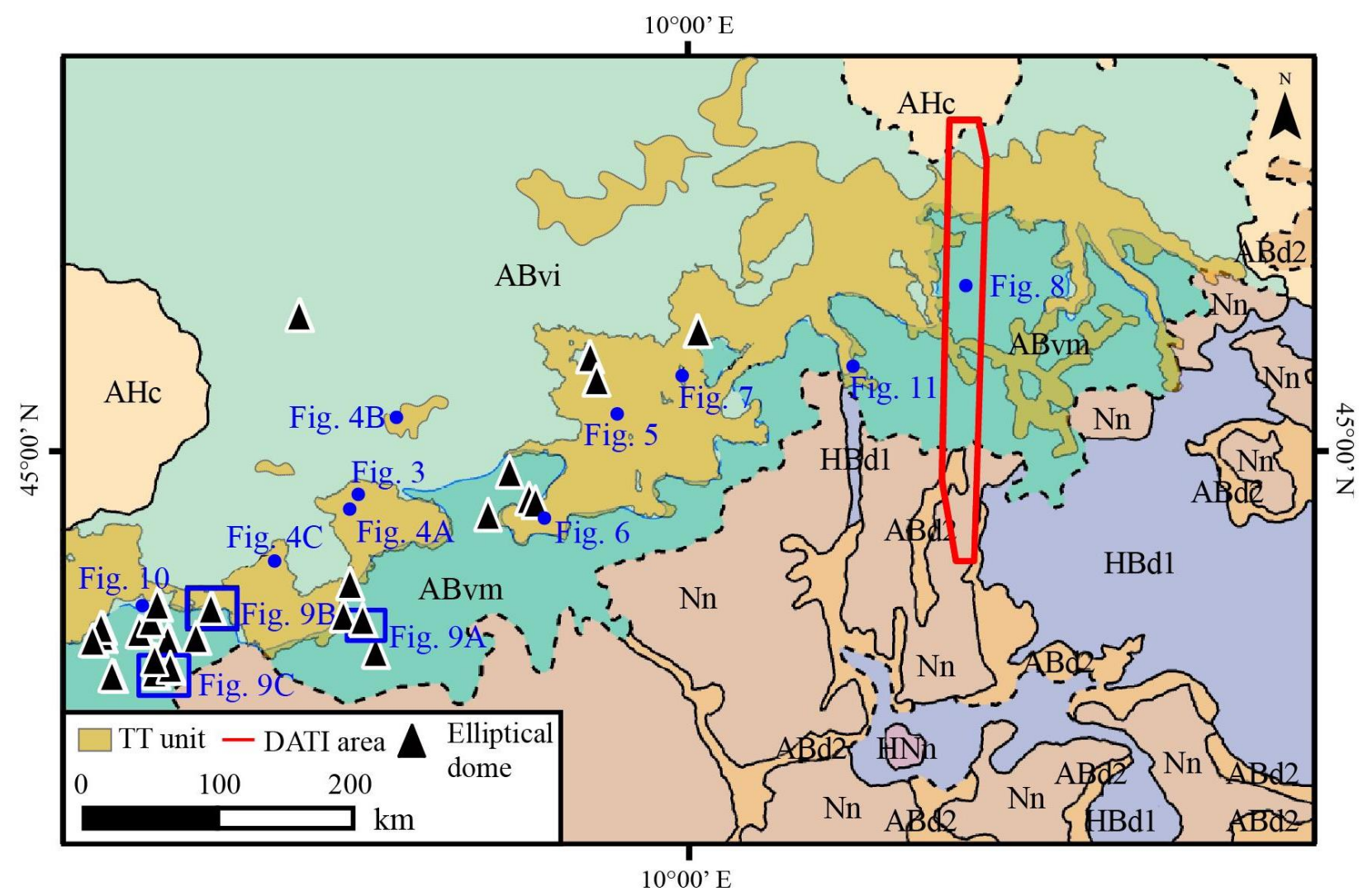

Figure 2. Background geological map is 'US Geological Survey Sci. Inv, Map 2888' by Tanaka et al., 2005. Lobate TT unit extension is marked by the orange polygons and covers an area bigger than $10^{5}$ $\mathrm{km}^{2}$. Red frame indicates the area of quantitative thermal inertia analysis (See section 3). Elliptical domes related to the thumbprint terrain (see Fig. 9-10) are localized outside or along the boundary of the thumbprint area (black triangles are not to scale). The lobate TT unit was mapped crossing both the Vastitas Borealis interior unit (ABvi) and Vastitas Borealis marginal unit (ABvm). Other geologic units: Nn - Noachis Terra Unit; HBd1 - Deuteronilus Mensae unit 1; ABd2 - Deuteronilus Mensae 2 units; HNn - 
Nepenthes Mensae unit. See Tanaka et al. 2005, for a more complete description. Courtesy of NASA/USGS.

\section{Data and Methods}

Context Camera (CTX; 6m/pixel) (Malin et al., 2007) and High Resolution Imaging Science Experiment (HiRISE; 0.25-0.32m/pixel) (McEwen et al., 2007) images were used to investigate thumbprint terrain. CTX images provided a full coverage of the study area to be compared with Mars Orbiter Laser Altimeter (MOLA; Smith et al., 2001) digital elevation model (DEM) which provided the topographic base map with a spatial resolution of $463 \mathrm{~m}$. Detailed topographic profiles were performed from MOLA laser shots (vertical resolution: $50 \mathrm{~cm}$; size of the laser shot on the surface: $128 \mathrm{~m}$ ) to investigate and to provide a topographic context for TT morphologies and associated lobate deposits (e.g. Fig.3 and following) thanks to MOLA Precision Experiment Data record (PEDR) facility available at the Photothèque Planétaire d'Orsay, France (http://fototek.geol.upsud.fr/-Mars-Orbiter-Laser-Altimeter-.html). Mars Odyssey (ODY) Thermal Emission Imaging System (THEMIS) daytime and night-time infrared (IR) images (100m/pixel; Christensen et al., 2004) were also used to investigate the thermophysical properties, including thermal inertia that quantifies the physical properties and average particle sizes of surface textures and morphologies (Fergason et al., 2006). Relief characteristics (slopes and aspects) for the relief correction of albedo and temperature difference (input parameters in Eq. 1) were calculated based on the High Resolution Stereoscopic Camera (HRSC) DEM-s (spatial resolution: 100 m; Neukum and Jaumann, 2004; Jaumann et al., 2007) in *da4.img format (aeroid directly comparable with MOLA grid) acquired from Mars Orbital Data Explorer (http://ode.rsl.wustl.edu/mars/).

\subsection{Thermal inertia estimation}

We performed a quantitative detailed analysis of thermal inertia on a selected portion of the studied area (Fig. 2). As direct measurement of thermal inertia was not possible to estimate; Differential Apparent Thermal Inertia (DATI) was computed as follows:

$$
D A T I=\frac{1-A}{\Delta T}
$$

1 where $\mathrm{A}$ is the albedo and $\Delta \mathrm{T}$ is the temperature difference. DATI technique (Sabol et 2 al., 2006) is proportional to $P$ ('direct' thermal inertia) and is calculated based on short 
time (t) intervals (at least one hour time difference) with a high $|\Delta T / \Delta t|$ gradient (in the morning or in the afternoon), preferably during the same period of the year (similar solar longitude).The selected part of SE Acidalia Planitia was chosen on the base of: (i) data availability for DATI calculation (i.e., high quality images with appropriate time interval, in the same period of the year), and (ii) the presence of the key landforms (thumbprint terrain). THEMIS IR images were processed online using the Themis Processing Web Interface (THMPROC; http://thmproc.mars.asu.edu). To calculate the Differential Apparent Thermal Inertia (Eq. 1), high quality THEMIS images were chosen: the minimum and maximum "summing" parameters were set to 1 (full-resolution images), while the minimum and maximum "image rating values" were set to 4 and 7 , respectively. These parameters depend on a subjective assessment of the image quality ranging from 1 (unusable) to 7 (very good); this assessment includes consideration of exposure, missing lines, instrument noise, and atmospheric features. Relief correction for $\mathrm{A}$ and $\Delta \mathrm{T}$ was also performed since this kind of calibration is not included in thermal inertia modelling. Temperature difference $(\Delta T)$ was additionally calibrated against total incoming energy. Atmospheric correction was also included. In order to avoid large errors by calculating DATI and albedo, the cells with $\mathrm{i}>79^{\circ}$ were excluded from the calculations.

The uncertainty in DATI calculation arises from errors due to dust opacity, albedo and slope inclination. The errors in daytime THEMIS temperatures may be $\pm 3 \mathrm{~K}$ (Fergason et al., 2006). Assuming the temperature amplitude is $20 \mathrm{~K}$ and albedo is $0.2, \mathrm{a} \pm 3 \mathrm{~K}$ error implies $17 \%$ relative error on thermal inertia due to the error of each of two measured temperatures. Dust opacity is $1.6 \mathrm{~J} \mathrm{~m}^{-2} \mathrm{~K}^{-1} \mathrm{~s}^{-1 / 2}$ making up $0.8 \%$ of the average DATI, (200 $\mathrm{J} \mathrm{m}^{-2} \mathrm{~K}^{-1} \mathrm{~s}^{-1 / 2}$ ), and standard deviation (SD) due to seasonal variation of dust opacity in the high-dust season, which is 0.1 . We estimate that a dust opacity error of 0.1 generates a relative error of $5.6 \%$ on apparent thermal inertia by comparing average DATI values corrected for dust opacities of 0.22 (average), 0.32 (average $+1 \mathrm{SD}$ ) and 0.12 (average $-1 \mathrm{SD}$ ). Considering the two errors of $0.8 \%$ and $5.6 \%$, the total uncertainty related to dust opacity is $5.7 \%$ when applying the rule of error propagation for error addition. The uncertainty of albedo calculation is $8 \%$ which generates a $1.5 \%$ error on DATI values. The error in computation of slope inclination on HRSC DTM is $\sim 4^{\circ}$ (Heipke et al., 2007), which can potentially add up to $35 \%$ of error on DATI values where the incidence angle is very high $\left(79^{\circ}\right)$. This is calculated by 
comparing DATIs for $79^{\circ}$ to the average DATI for $75^{\circ}$ and $83^{\circ}$, provided all other parameters are fixed at typical values. In the most common case where the incidence angle is in the range $0^{\circ}-50^{\circ}$, the DATI error is within $10 \%$. Taking temperature, dust opacity, slope inclination and albedo into account, the total uncertainty on DATI is estimated to be within $27 \%$. However, it can reach up to $43 \%$ when the incidence angle is $79^{\circ}$.

We performed a crater counting analysis using CTX imagery to provide an age estimation for the lobate TT unit deposits. All visible impact craters ( $>500 \mathrm{~m}$ in diameter) were measured except the aligned secondary clusters and rays within the CTX resolution limit using the ArcGIS add-in CraterTools (Kneissl et al., 2011; Bamberg et al., 2013). The crater-size frequency distribution (CSFD) was plotted and the crater retention ages were calculated with Craterstats by visually selecting the portion of the crater size-frequency distributions that is parallel to some isochrons between steps of the distribution (Neukum, 1983; Hartmann and Neukum, 2001; Platz et al., 2013).

\section{Results}

Thumbprint terrain was usually described as sets of alternating ridges/mounds and depressions, with high and low albedo respectively, up to several tens of kilometres in length (Fig. 1A; Lockwood et al., 1992). However, we observed no noticeable variations of alternating relief by using MOLA laser shots in our study area (Fig. 3). The low albedo surfaces show a darker rough surface, while the high albedo areas show alignments of poorly expressed mounds (Fig. 4A) that can individually be dome-like (Fig. 4B) or more rarely conical (Fig.4C) when seen at high resolution. 

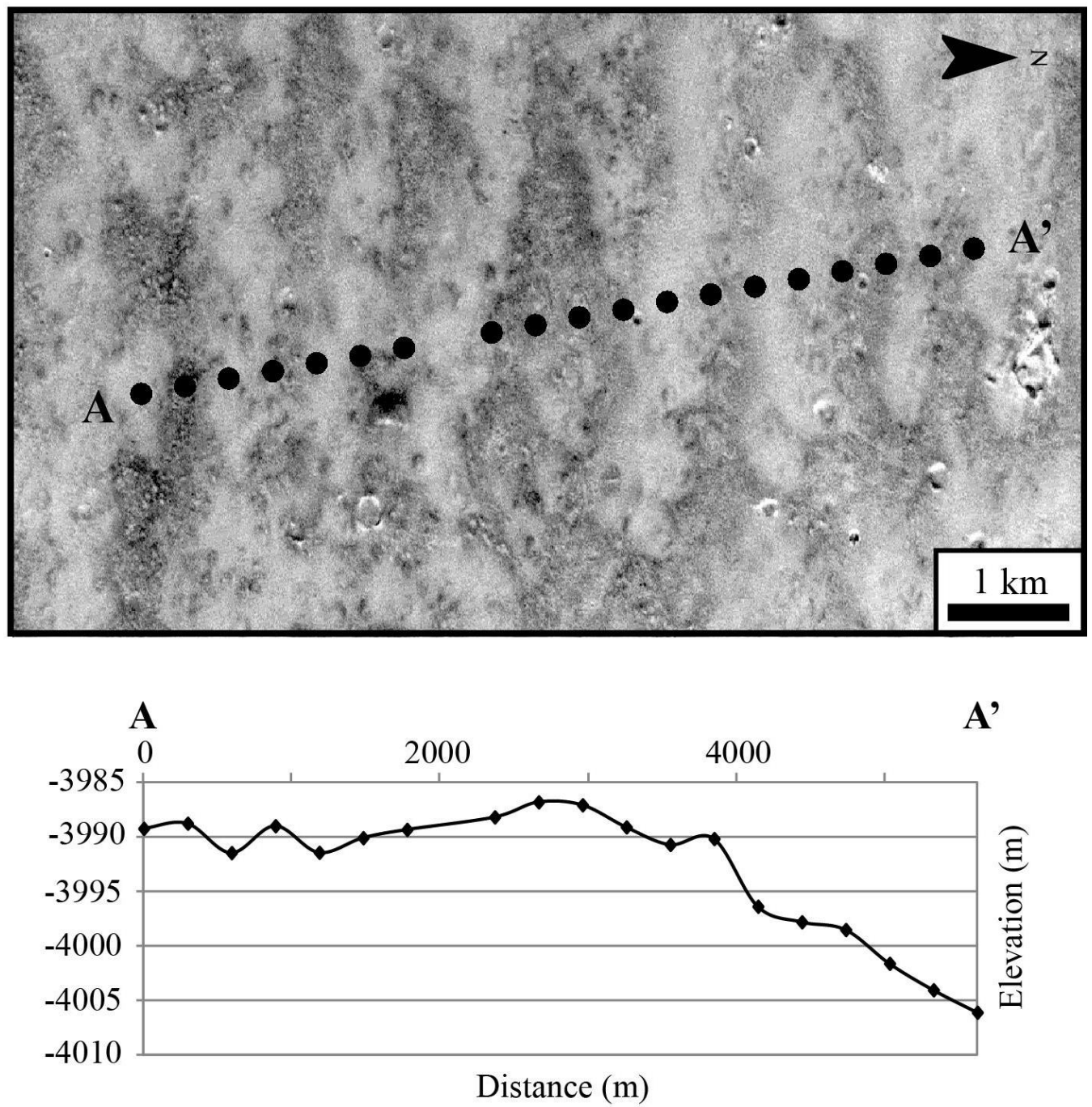

Figure 3. Topography of the thumbprint terrain. A topographic profile crossing the high and low albedo area was performed by using MOLA laser shots. No clear topographic alternation is observed between the two areas. The black points represent the approximate size of the laser shot on the surface $(128 \mathrm{~m})$ according to Smith et al., 1999; 2001 (CTX image $n^{\circ}$ B17_016195_2250). North is oriented 90 degrees right. Courtesy of NASA/ JPL/Univ. of Arizona. 


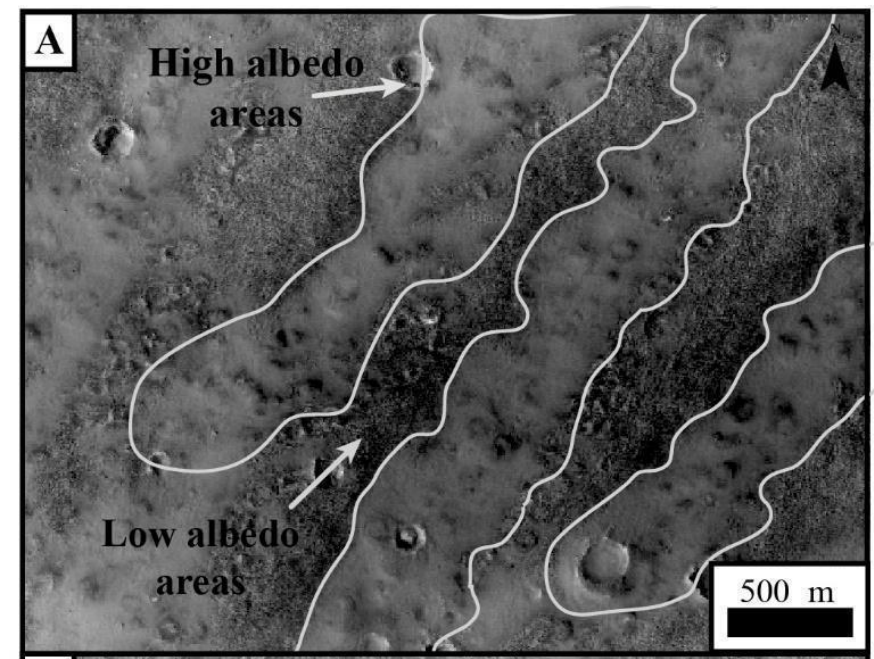

Figure 4. Morphology of thumbprint terrain at high resolution. A) High albedo areas include mounds and pits while low albedo areas are composed of a rough surface (HiRISE image: ESP_011949_2255). The high albedo areas of the thumbprint terrain include mounds that may be $B$ ) dome-like (HiRISE image: PSP_001928_2265) or more C) cone-like shaped mounds (CTX image: P22_009747_2239). The former type is usually bigger in diameter than the latter, but no clear correlation was found. Courtesy of JPL/Univ. of Arizona. 
Thermal inertia comparisons showed that thumbprint terrain is brighter than the surrounding terrain in day-time THEMIS images, whereas it is darker in night-time ones (Fig. 5). Moreover, the whole lobate TT unit is also generally brighter in day-IR images in comparison to the surrounding plains and plateau units, so we readily defined the lobate TT unit limit realizing: (i) TT is also present in the ABvm unit, although previous literature (Tanaka et al., 2005) considers that it extends only within the ABvi unit (Fig. 2) and (ii) it covers an extensive surface greater than $10^{5} \mathrm{~km}^{2}$ in southeastern Acidalia Planitia.
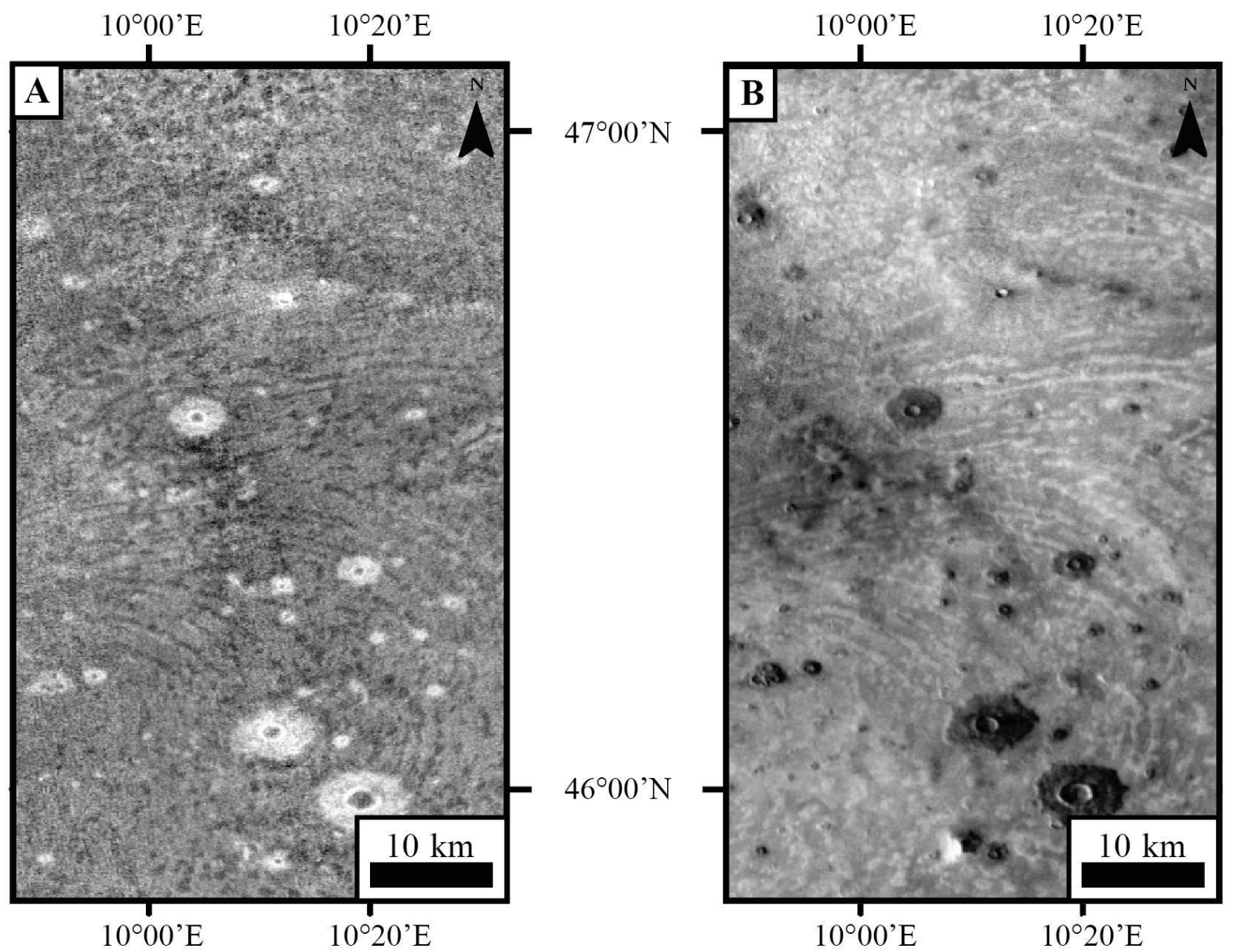

Figure 5. THEMIS daytime and night-time infrared images of thumbprint terrain. The low albedo areas are darker in night-time images $(A)$ and brighter in daytime ones $(B)$. Night-time image resolution is lower than the daytime resolution.

Unfortunately, the northern limit of the lobate TT unit in Acidalia Planitia is covered by a unit of lower albedo that has a constant elevation of around $-4100 \mathrm{~m}$ (supplementary material). Therefore, the true extent of the unit remains unknown. In the southern region of the study area, the lobate TT unit covers the plateau and valleys near the dichotomy. The southern boundary of the unit is marked by several lobate features with peripheral and lateral ridges that sometimes overlap each other in the Deuteronilus valley system 
93 (Costard et al., 2017). The lobes are found inside valleys or on lateral valley plains 94 between $-3860 \mathrm{~m}$ and $-4001 \mathrm{~m}$ altitude.

95 We also observed that lobes are oriented upslope of few degrees (Fig. 6), or on residual 96 hills plains (Fig. 7), reaching a maximum thickness of $10-20 \mathrm{~m}$ by using MOLA laser 97 shots (Costard et al., 2017). Occasionally, the characteristic alignments of 98 cones/mounds tend to distance themselves approaching the edge of the lobate TT unit 99 and do not show the characteristic high albedo small mound chains. Regardless, we 100 included them in the thumbprint terrain unit due to thermal inertia comparisons with 101 surrounding areas, lateral continuity and sparse presence of clusters or individual small 102 mounds. A general southeastward trend has been computed from the analysis of the 103 high albedo mounds (Fig. S1 - supplementary material), even if there are some lobes 104 with random direction because of first-order topographic influence (Fig. S2 105 supplementary material). 

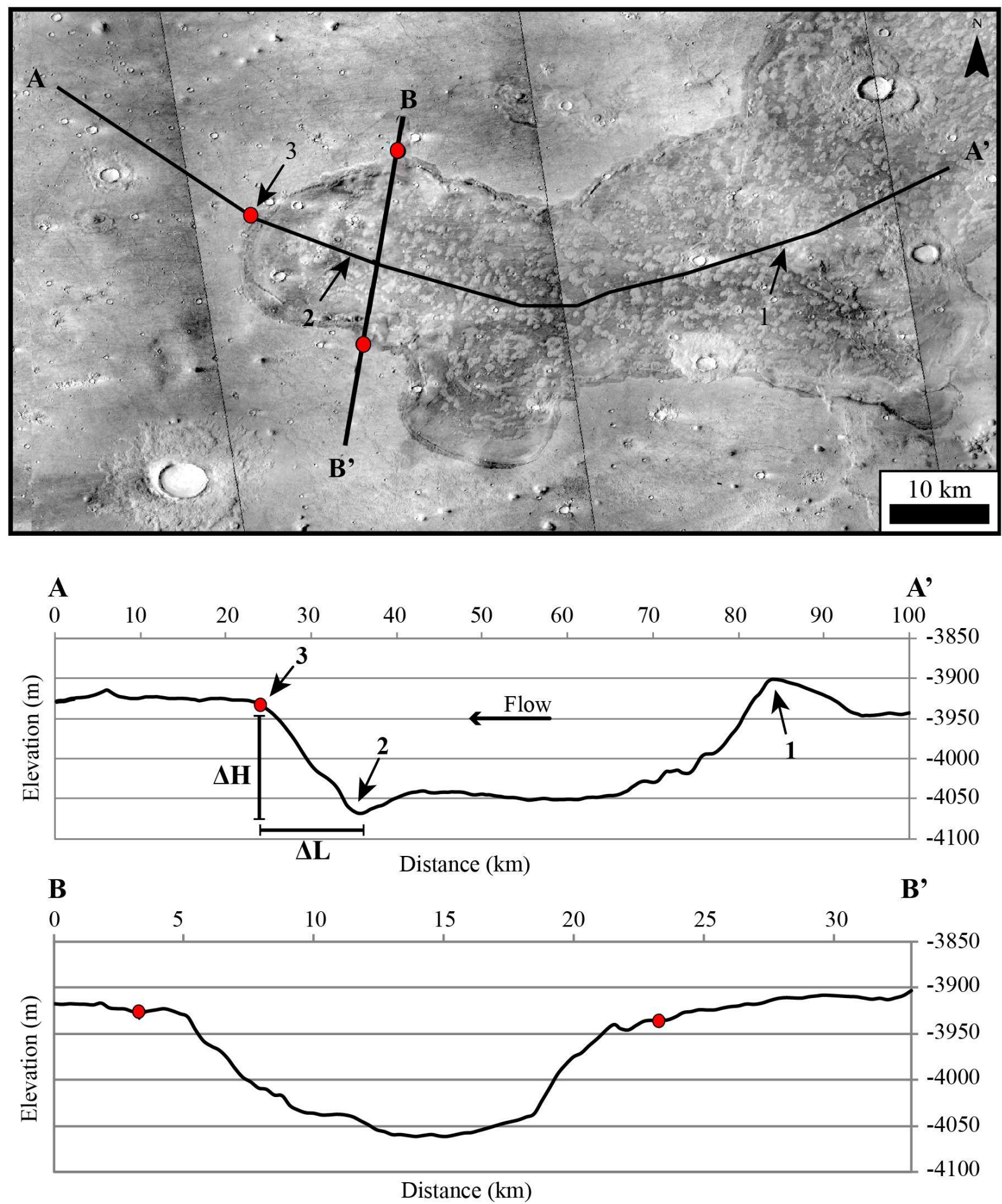

Figure 6. Longitudinal profile $\left(A-A^{\prime}\right)$ and cross-section $\left(B-B^{\prime}\right)$ of a southern limit lobate TT unit deposit from MOLA DEM. $\triangle L=12000 \mathrm{~m} ; \Delta H=138 \mathrm{~m}$. Lobate TT unit limits are marked by red dots on the image and on 110 profiles as well. Relative slope value is $\approx 0.70^{\circ}$. CTX images: P18_008112_2251; P18_007901_2250;

111 P18_008046_2253; P21_009338_2253. 

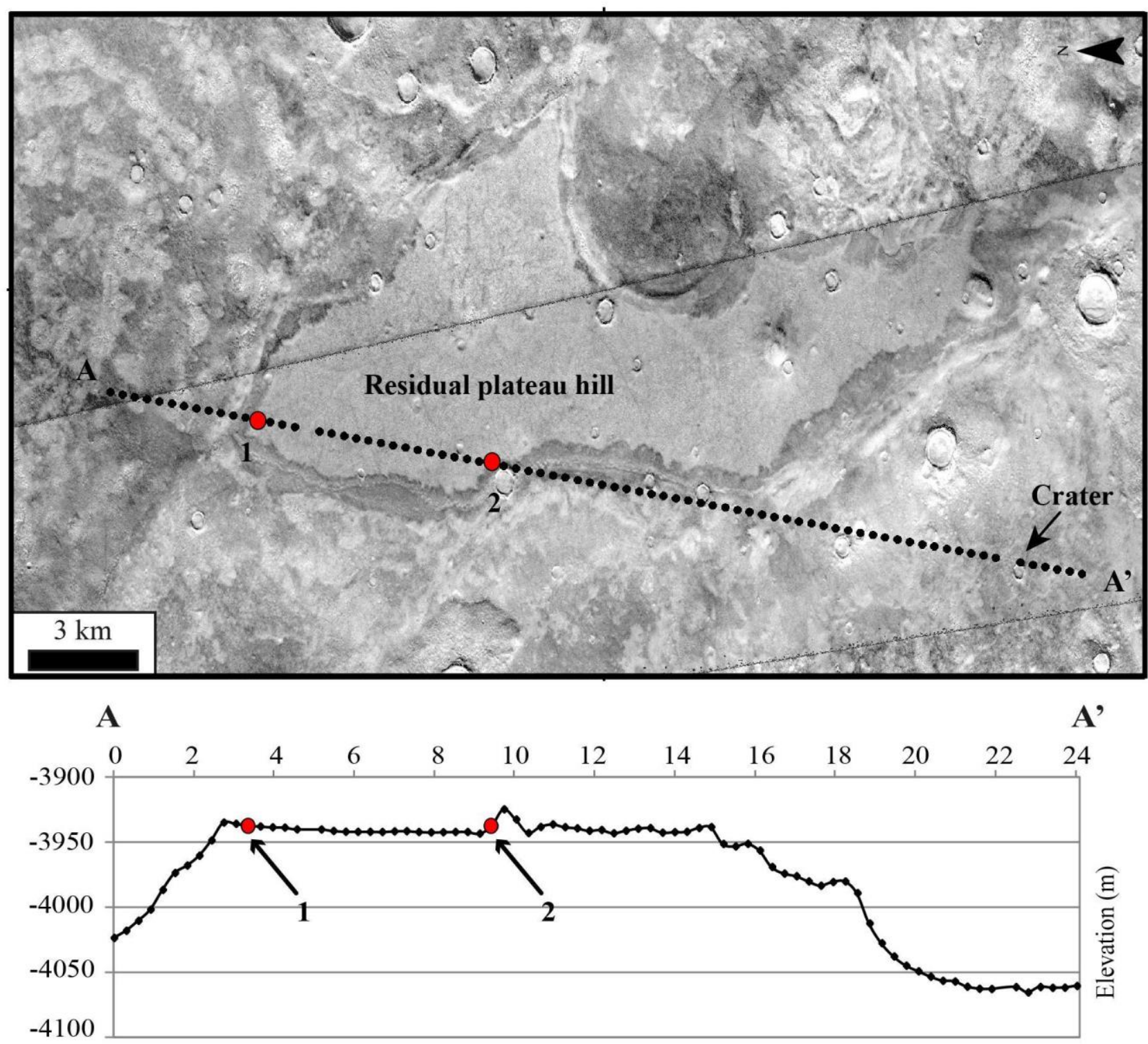

Distance (km)

Figure 7. Thumbprint terrain deposits can move upslope reaching plateau residual hills. Thumbprint terrain limit that is marked by red dots on the image and on A-A' MOLA shots profile as well (CTX image: B02_010261_2248). North is oriented 90 degrees left.

116 Thermal inertia was calculated based on the IR THEMIS data for the part of the 117 thumbprint terrain unit (marked by the black line on Fig. 8A). For this area, DATI values 118 ranges from 171 to 311 indicating fine particles ( 40 - 500 $\mu \mathrm{m}$ : silt to medium sand) 119 with the average particle size of $125 \mu \mathrm{m}$ (Fergason et al., 2006; Wentworth, 1922). An 120 average albedo of 0.19 (range $0.15-0.33$ ) calculated for this region based on CTX 121 images further supports the presence of silt and fine sand. (Fig. 8 B). 


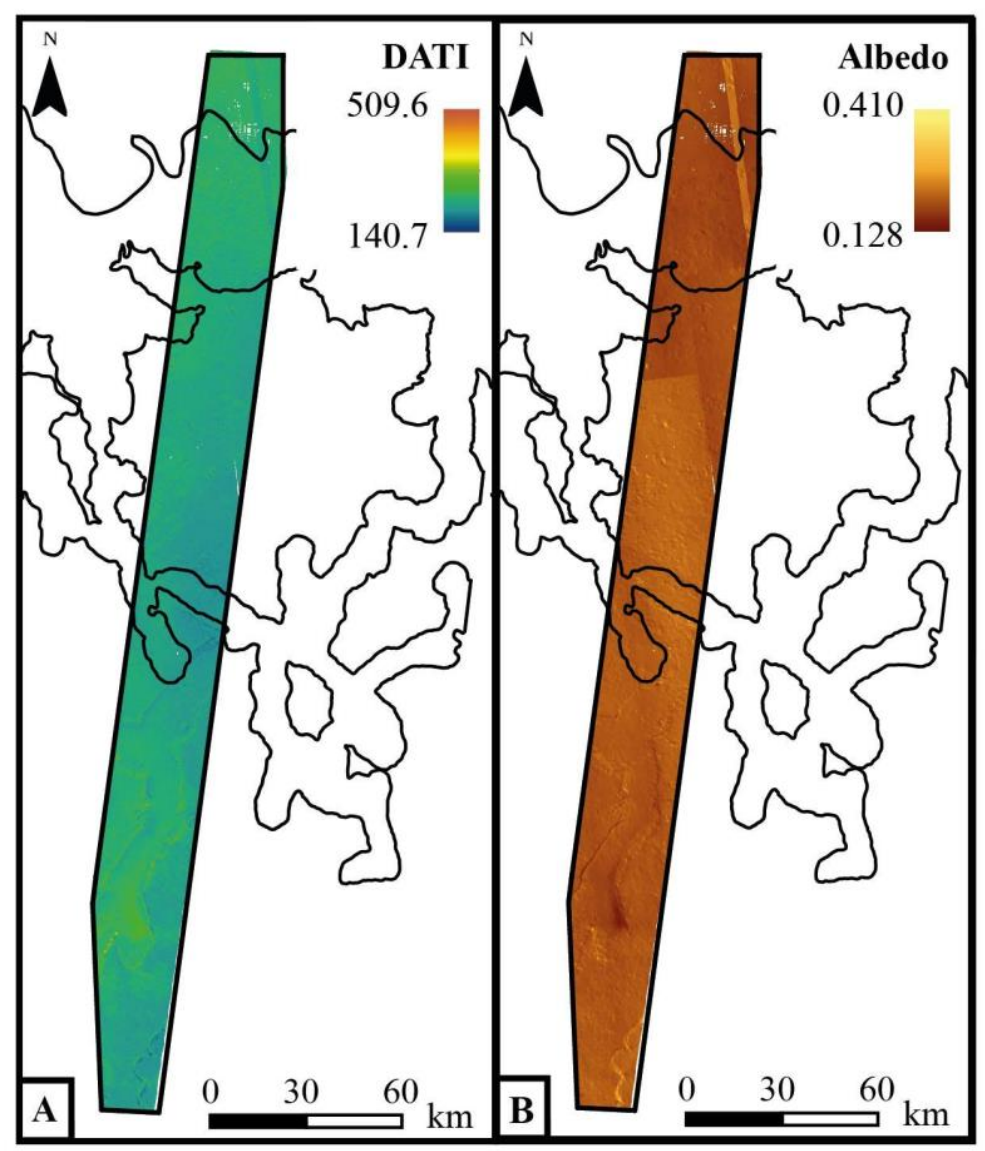

Figure 8. Thermal inertia analysis. A) DATI $\left(\mathrm{J} \mathrm{m}^{-2} \mathrm{~K}^{-1} \mathrm{~s}^{-1 / 2}\right)$ values for the selected part of the study area shown in Fig.2. B) albedo values. Lobate thumbprint terrain unit extension is marked by the black line. The location of Fig. 8 is also shown in Fig.2. Top-left corner coordinates: $15^{\circ} 39^{\prime} 58.366^{\prime \prime} \mathrm{E}$; $49^{\circ} 41^{\prime} 20.1711^{\prime \prime} \mathrm{N}$.

\begin{tabular}{|l|c|c|}
\hline \multicolumn{1}{|c|}{ Material } & $\begin{array}{c}\text { DATI } \\
\left(\mathbf{J ~ m}^{-2} \mathbf{K}^{-1} \mathbf{s}^{-1 / 2} \text { ) }\right.\end{array}$ & $\begin{array}{c}\text { Particle } \\
\text { diameters }(\boldsymbol{\mu m})\end{array}$ \\
\hline Dust & $\sim 150$ & $\sim 45$ (silt) \\
\hline \multirow{2}{*}{ Sand } & $\sim 200$ & $\begin{array}{c}\sim 160 \text { (very fine } \\
\text { sand/fine sand) }\end{array}$ \\
\cline { 2 - 3 } & $230-270$ & $\begin{array}{c}290-575 \\
\text { (medium sand) }\end{array}$ \\
\hline Rock & 1200 & \\
\hline
\end{tabular}

Table 1. Comparative DATI values $\left(\mathrm{J} \mathrm{m}^{-2} \mathrm{~K}^{-1} \mathrm{~s}^{-1 / 2}\right)$ and particles diameters $(\mu \mathrm{m})$ of selected materials (after Fergason et al., 2006).

131 We observed several domes (10-12 kilometres in diameter) near or along the lobate TT 132 unit limit (Fig. 2), making their detection difficult inside thumbprint as the lobate TT unit 133 overlaps them (Fig. 9B). These morphologies are mostly elliptical, have an irregular and 134 lobate edge and show concentric features compared to the central peak (Fig. 9A; Fig. 135 9B). Smaller features ( $\approx 1 \mathrm{~km}$ in diameter) are observed, but are almost circular and do 
not show clear concentric lineaments (Fig. 9C). MOLA elevation profiles showed they have a symmetric profile and heights of few tens of meters as shown in Fig. 9A. Thermal inertia comparisons show that these domes are very bright in day-IR images and darker in the night compared to the surrounding units (Fig. 10). This characteristic is qualitatively similar to the response that thumbprint terrain has to night/day material exposition. In fact, TT is also generally brighter in day-IR images, whereas it is darker during night acquisition (Fig. 5).
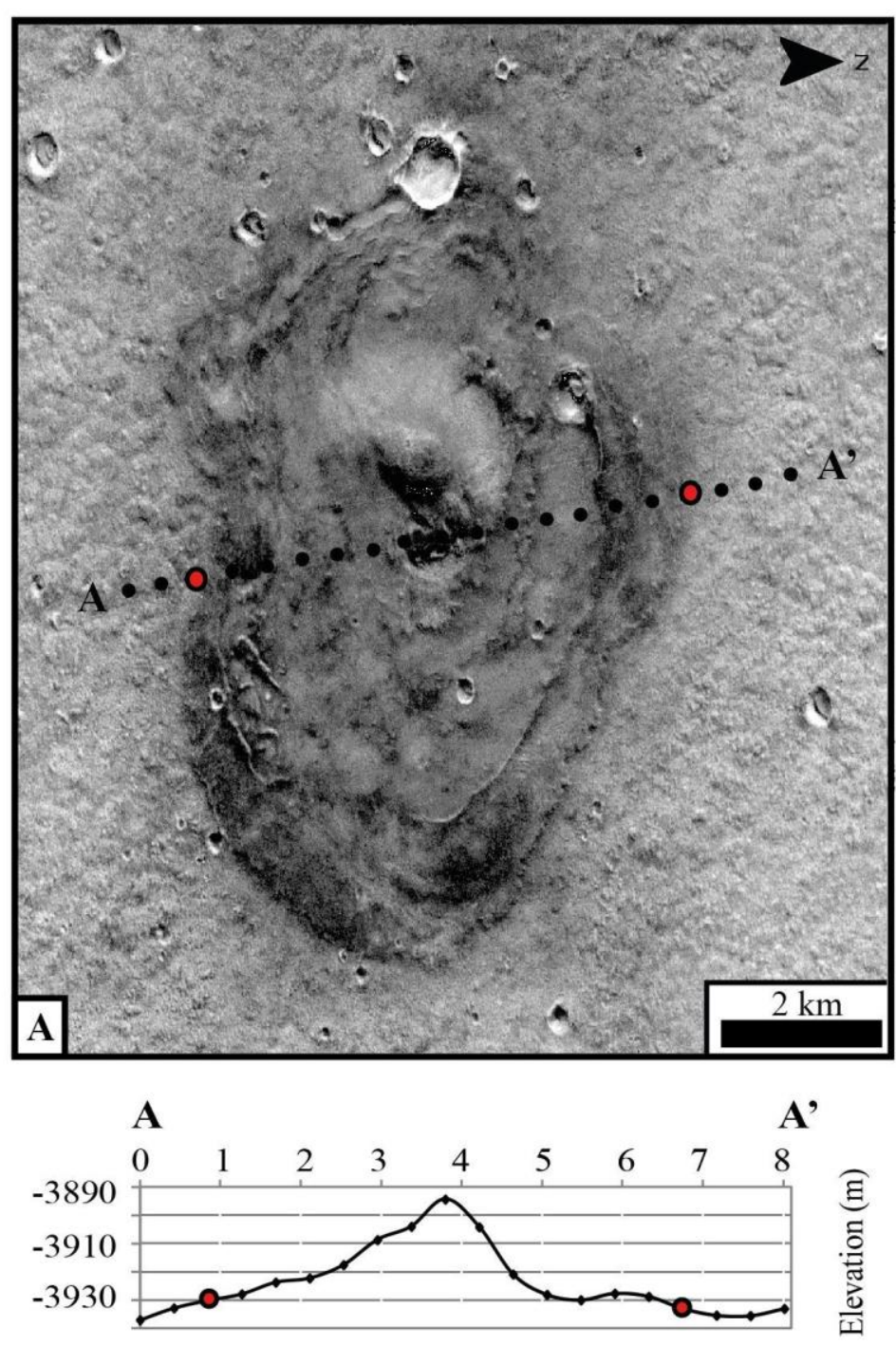

Distance $(\mathrm{km})$
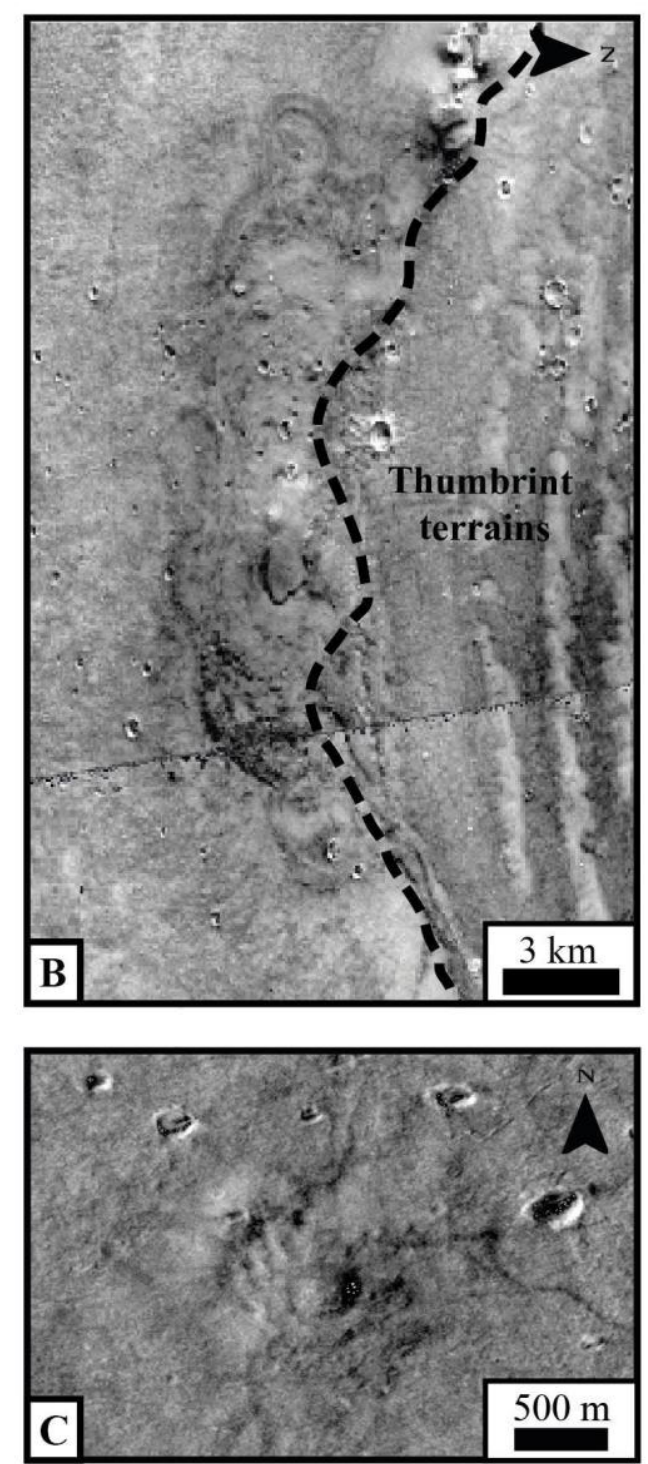

Figure 9. Large domes underlying thumbprint terrain unit. A) MOLA laser shot cross-section cutting a dome that is found outside thumbprint terrain unit. Central peak and some relating concentric features are visible. The edge is elliptical and quite regular. The boundary is marked by red dots. Dome height is $\approx 40 \mathrm{~m}$ (CTX image: B17_016195_2250). North is oriented 90 degrees right. B) Dome overlapped by thumbprint terrain. Black dashed line marks thumbprint terrain unit limit. Central peak, some concentric features and an irregular and lobate edge are observed. (CTX image: 


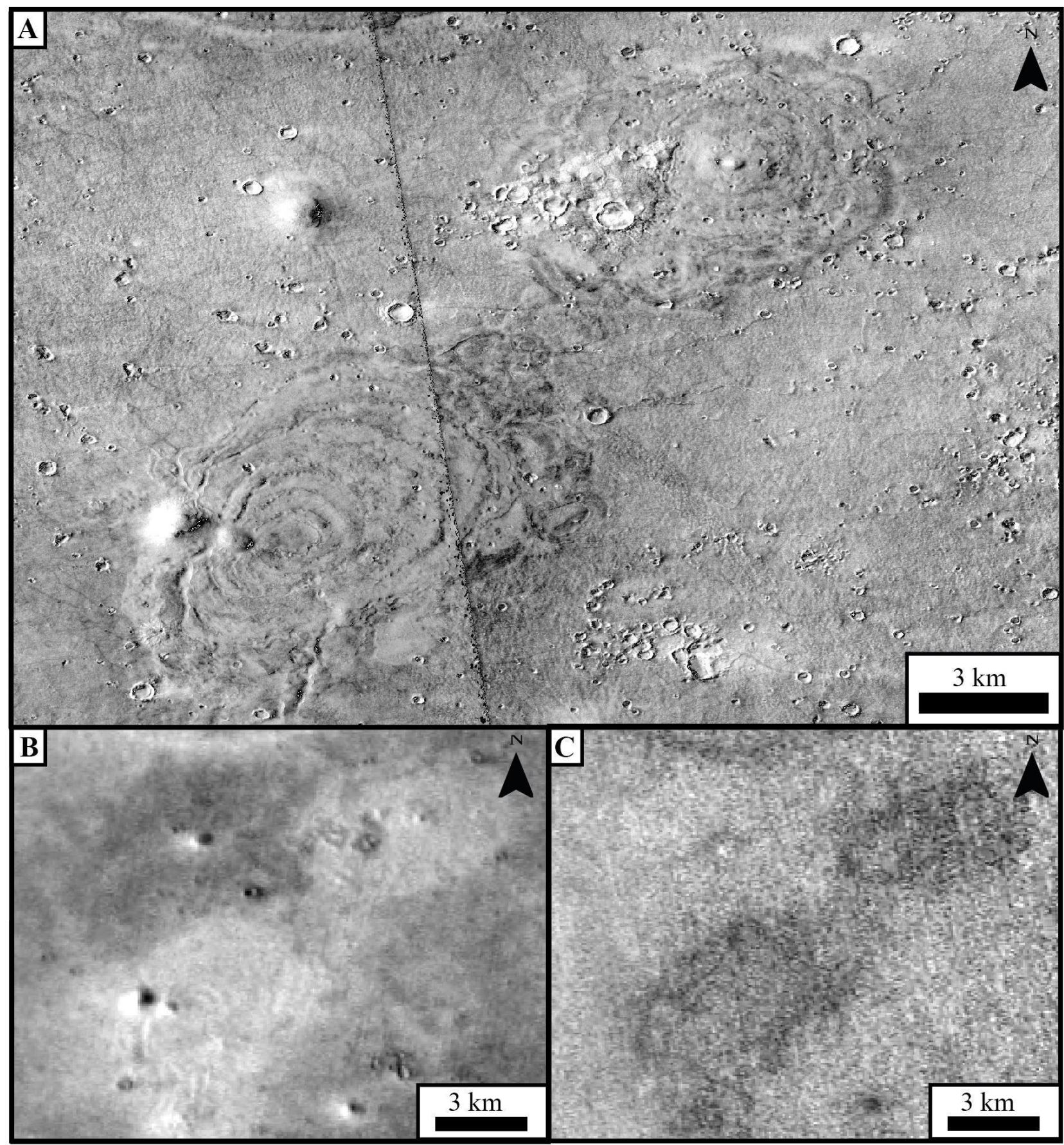

Figure 10. Large domes several kilometres across underlying thumbprint terrain unit in visible CTX-scale (A). Thermal inertia response in day- and night-time acquisitions. THEMIS images show that domes are brighter in daytime $(B)$ and darker in night-time (C) compared to surrounding areas. Night-time image resolution is lower than daytime image. CTX images: P21_009246_2240; G23_027087_2234. 
160

161

162

163

164

165

166

167

168

169

170

171

172

173

174

175

176

177

178

179

180

181

182

183

184

185

186

187

188

189

190

191

192

Since the most recent hypotheses have already provided a regional geological framework for lobate deposits in Acidalia Planitia (Rodriguez et al, 2016; Costard et al, 2017; Costard et al., 2019 ), in the following paragraphs we will discuss and consider the characteristics of thumbprint terrain to each of the main geological scenarios (i.e., pingoes, volcanic cones, liquefaction, mud-volcanoes, and tsunami-related deposits) in order to reconcile and insert TT origin in the regional context.

Although the scenario of a periglacial environment has been put aside in favour of more conceivable interpretations in the last years, Rodriguez et al. (2016) did not totally dismiss this hypothesis because tsunami deposits could have frozen and formed a layer of permafrost. Moreover, the presence of excess ejecta craters strengthens the occurrence of an icy sub-surface layer that could also be responsible for surficial geological processes as proposed for other geological processes in other areas on Mars (Salese et al., 2016). However, pingoes are domical structures formed by freezing and swelling of groundwater and are, therefore, composed by the same material as their surroundings. Thus, the difference observed between the pitted mounds and the darker adjacent areas in THEMIS images are not consistent with a pingo hypothesis (Fig. 5). Furthermore, the growth of pingoes is accompanied by radial extension cracks (Mackay, 1973; 1998), which were not observed in any of our target features and deposits. The high albedo mounds have been also interpreted as moraines, or ice-cored ridges associated with a former glacial environment (Lucchitta, 1981; Rossbacher and Judson, 1981; Farrand and Gaddis, 2003), but their exact origin is still under debate. Herein, we find the periglacial origin hypothesis problematic because of thermal inertia comparisons with surrounding deposits (Fig. 5), material viscous behaviour that is not consistent within a periglacial or glacial environment, and the lack of typical glacial features such as polygons, cracks, eskers, drumlins and kettle holes.

Alternatively, over many decades, the associated underlying TT lobate deposits have also been interpreted as lava flows flooded over a broad region forming a volcanic plain. In this scenario, the high albedo mounds are interpreted in a variety of ways including: 1) rootless cones (pseudocraters) formed by explosions that resulted from a lava flow advancing over a wet substrate (Frey and Jarosewich, 1982); 2) cinder cones formed by explosion and deposition of ashes (Wood, 1979); or 3) tuff cones resulting from the explosive interaction between rising magma and water/groundwater (Wohletz and Sheridan, 1983). However, thumbprint terrain mounds are brighter than basaltic sands 
193 in Acidalia (Farrand et al., 2005) and the DATI values of the TT are much lower than the ones expected for lava flows (Fig. 8; Table 1). In addition, volcanic cones do not form in arrangements that resemble patterns observed within TT. Based on the lack of these conditions, we conclude that a volcanic origin of the thumbprint terrain is unlikely for TT in southeastern Acidalia Planitia.

More recently, thumbprint terrain has also been interpreted as mud volcanoes which formed after the freezing of an ancient standing body and/or rapid sedimentation and diagenesis. The existence of a mud sheet flood has also been proposed for the northern lowlands due to some hills and ground undulations in Isidis Planitia and Mare Australe (Farrand et al., 2005; Oehler and Allen, 2010; Souček et al., 2015; Komatsu et al., 2016). As outflow channels filled northern lowlands (Baker et al., 1991; Carr and Head, 2003), the following ice sublimation mostly depended on the accumulation rate of debris on the surface. Sublimation residue would have formed the Vastitas Borealis Formation units. Even a shallow layer of little debris thickness would have decreased sublimation and favoured freezing (Farmer and Doms, 1979; Carr, 1990; Carr and Head, 2003): both the gradual freezing and the load of the top debris layer make the internal pressure rise. This could have led to mixtures of water, ice, rock/soil and mud expulsion on the surface as proposed in Utopia Planitia in order to explain etched flows and polygonal troughs (Ivanov et al., 2014). This model can also be applied to the thumbprint terrain in Acidalia Planitia since geologic observations and settings are similar. The high albedo mounds could be analogous to terrestrial mud volcanoes with a wide range of different features from meter sized cones to domical structures hundreds of meters in size (Kholodov, 2002) that are similar in lateral and vertical dimension to the Martian domes and cones of the Acidalia region. However, thermal inertia and albedo values indicate a widespread presence of fine sand and silt (mud?) size grains. The reason could be explained by two fundamental factors that eventually interacted with each other. First, detectable grain-size values might not match mud particle size anymore since the material dried up and got indurated over the time. Ultimately, sandy mud volcanoes have been found on Earth (Miyakawa et al., 2013) and, thus, this phenomenon cannot be excluded either.

Furthermore, we need to take into account the coexistence of TT with lobate underlying deposits which points to flows with a certain viscosity: the lobate deposits with peripheral ridges clearly indicate that viscous material flowed inside southern valleys 
(Fig. 6; Fig. 11; supplementary material) and that the plateau and hills were partially flooded (Fig. 7; Fig. S1- supplementary files). Additionally, parallel and arcuate alignments of mounds/cones (thumbprint terrain) observed together around obstacles as knobs, residual hills, and plateaus (Fig. 1A, white arrow, Fig. S1- supplementary files), perfectly follow the inferred underlying lobate deposits flow direction (Fig. 11, Fig. S1 and Fig. S2- supplementary material). In the occurrence of an impact-generated tsunami: obstacles might have first influenced flow direction and speed (tsunami wave fronts), forming thumbprint terrain in parallel and curvilinear patterns. Nevertheless, an impact-generated tsunami provides an explanation to the main concern about the energy required to flow up slopes and reach topographic heights. In a previous work, three craters (30-50 km in diameter) were proposed (Fig. S3 - supplementary files) as the sources of the tsunami events, based on validated terrestrial models scaled to Mars (wave height, propagation, run up elevation, and distance) (Costard et al., 2017). The numerical tsunami simulations presented in Costard et al. (2017) link the TT alignments to interference patterns produced from the interaction between the tsunami fronts and the coastal topography. By binding the numeric simulation results to the morphological observations, we assert that a tsunami event contributed to the formation of TT mudvolcanoes.

On Earth, tsunamis move landward in a series of wave fronts (Lavigne et al., 2009), whose energy and interaction with the shoreline topography results in different inundation distances and distributions of lobate debris. Within the complex topography of flat-floored valleys and plateaus along the Martian dichotomy boundary, the interference of the multiple reflected and refracted waves that are observed in simulations explain the flow distribution itself and the origin of the arcuate and parallel pattern that characterizes the thumbprint terrain. Thumbprint terrain cones are not observed in any terrestrial tsunami, but they are herein considered mud volcanoes that formed as a consequence to an overpressure caused by rapid compaction upon deposition of the transported material during the final stage of a tsunami. A similar geological process was proposed for the emplacement of the Vastitas Borealis Formation in both Chryse and Acidalia Planitia at the regional scale (Salvatore and Christensen, 2014). According to this hypothesis, the Vastitas Borealis Formation would be a product of extensive sedimentary modification both during and immediately after outflow channel activity. Mud-extrusion would then result from burial and rapid 
compaction of previously saturated deposits (Salvatore and Christensen, 2014). In our 260 study area, rapid compaction could have expelled a mixed water-mud material, 261 preferentially along the front, and would explain 1) the arcuate or random pattern of 262 thumbprint terrain reflecting the tsunami propagation when influenced by obstacles (Fig. $1 \mathrm{~A}$ - white arrow) or not (Fig. 1A - black arrow), respectively and 2) the gradual disappearance of TT cones toward the unit boundary as compaction, and hence overpressure, should have decreased as the tsunami wave propagation progressively lost energy and material while moving 'landward'.

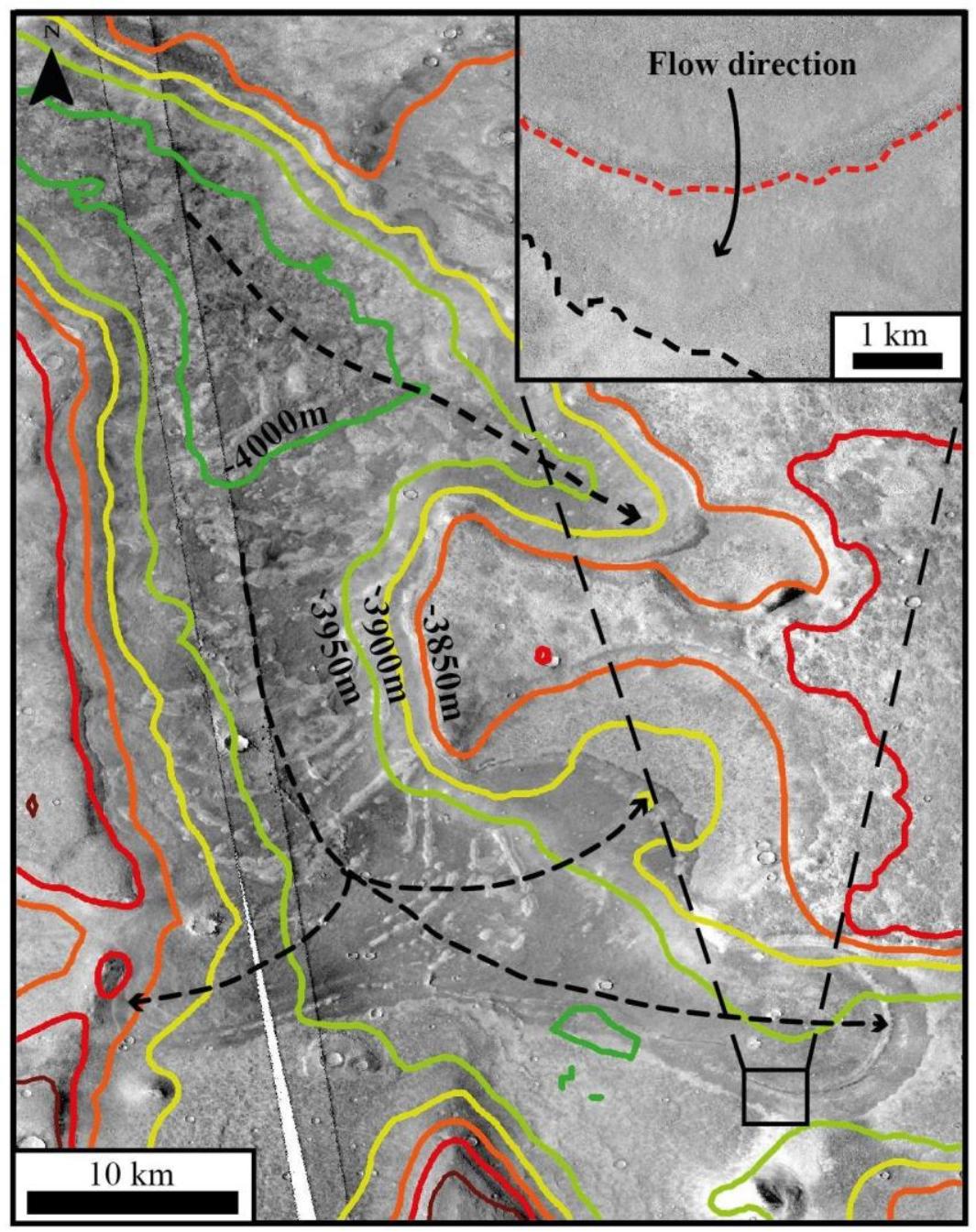

Figure 11. Lobes flow direction inferred from mounds alignments as marked by dashed black arrows. Contour lines are 50 meters spaced. They show that flows clearly go upslope. g18_025425_2271; b18 016498 2264. Inset: Thumbprint terrain flow exceeding valley scarp (dashed red line) for several kilometers. Unit limit is marked by the red dashed line. The lobe has no peripheral ridges and its front is lobate (HiRISE ESP_016498_2265).

274 On Earth, geophysical surveys and studies - across the continental margins of the Arctic 275 Ocean - continuously detect suites of hectometre/meter-wide seafloor mounds 
accompanied with seepage due to the destabilization of gas hydrates (methane)

277 trapped in seafloor and permafrost-associated sediments (Serov et al., 2015, 2017; 278 Andreassen et al., 2017). Pressure is increased by released methane and triggers 279 blowouts through weakened zones. The Holocene marine transgression affected the Arctic shelves and led to an extensive permafrost thawing; this is the reason why gas hydrate degradation occurs primarily on the circum-Arctic Ocean continental shelves (Macdonald, 1990; Lachenbruch, 1994; Maslin, 2010), where subsea permafrost thawing and methane hydrate dissociation have been triggered by warming and inundation since the Late Pleistocene. Seafloor mounds are steep-sided, up to $1100 \mathrm{~m}$ wide, generally semi-circular to elliptical in plan view, and have an irregular upper surface incised with straight or curved furrows. Since the mounds are elevated well above the surrounding seafloor, the most plausible formation mechanism is either deposition or uplift. However, the absence of any discernible seismic paleo-seafloor favours the former hypothesis (Andreassen et al., 2017). We find it difficult to attribute thumbprint terrain cones in Acidalia Planitia to these terrestrial shallow-water seamounds considering the scale, mutual geographic distribution, timing of formation and their absence in any terrestrial tsunami deposit since these Martian cones are smaller and more densely coalesced (whether organized or not) than Earth's features. Therefore, TT mounds/cones are more likely thought as mud-volcanoes related to a catastrophic event (tsunami) rather than a release of pressure that gradually accumulated in the sub-surface due to sediment deposition. However, these terrestrial gas blowouts cannot be ruled out for elliptical domes that have been observed outside or under the thumbprint terrain unit (Fig. 2; Fig. 9) and must be further investigated to fit the Acidalia Planitia thumbprint terrain and tsunami-related deposit. The same domes and thumbprint terrain mounds indicates that: 1) these features might be composed by the same material reflecting the uniformity of lithologies in Acidalia Planitia and 2) both elliptical domes and high albedo mound thumbprint terrain alignments are qualitatively finer grained or more poorly consolidated than surrounding areas. This behaviour fits well with average DATI values and conclusion (see section 4). Therefore, elliptical domes may be the result of material extrusion (due to gradual freezing and/or the load of top debris) prior to the extensive viscous flowing (tsunami event) that led to the thumbprint terrain unit overlapping them and making dome detection difficult inside the lobate TT unit. 
New findings stated that some TT is too young to have experienced the ocean floor environment, and, hence, a tsunami event, according to the current understanding of the cryosphere depth and thermo-chemical structure of Mars (De Toffoli et al., 2019). However, some areas of thumbprint terrain may be old enough to have experienced tsunamis. In De Toffoli et al., 2019, 370 Ma may be the age of a possible ice-rich mantle covering the older underlying TT deposit as it was observed in northern Arabia Terra where a similar thumbprint terrain is covered by young ice-rich ejecta from Lyot crater (48 $33^{\prime} 42.72 " \mathrm{~N} 18^{\circ} 12^{\prime} 46.78^{\prime \prime E}$ ). Moreover, when dating surfaces and bedforms, it has been observed that the floor ages of some Martian outflow channels generally equate to younger mesoscale flows (several hundred meters to a few kilometers) instead of those published in more general geologic maps reflecting older and regional scale processes (Rodriguez et al., 2015). If alignments of cones in Acidalia Planitia were as recent as those analysed in Arcadia Planitia (De Toffoli et al., 2019), their strict occurrence with lobate flow deposits direction and highly organized patterns around obstacles (hills or residual plateaus), matching a very older and distinct tsunami event flow, would be an unusually fortunate coincidence. Consequently, this firmly underlines the importance of investigating thumbprint terrain found in other areas of Mars. High-resolution images may further distinguish multiple TT sets: i) analysing adjacent deposits and the geological context in which they are formed, ii) evaluating origin and/or putative trigger mechanisms discerning any morphological convergence.

The ocean hypothesis remains controversial and explanations have been put forward to account for the presence of the TT in the absence of an ocean. For example, Skinner et al. (2008) proposed that the propagation of seismic surface waves through northern plains sedimentary units could have triggered liquefaction and run-up flows along the margins of these deposits. In conclusion, given the morphology, the scale, the thermal inertia analysis, the strict occurrence of thumbprint terrain within lobate deposits and their congruous spatial arrangement with inferred lobes direction, and the significant energy required to surmount little slopes, here we favour a tsunami-related origin for TT in Acidalia Planitia, rather than simply a mud-volcanism deposit.

\section{Conclusions}

This paper renewed questions about the presence of a large standing body of water on Mars by analysing thumbprint terrain, lobate morphologies and deposits in southeastern 
Acidalia Planitia. The most likely hypothesis is a tsunami-related origin, as lobate TT unit characteristics (e.g., viscosity, onslope flows, etc...), geological setting and numeric simulations are comparable to terrestrial tsunami deposits. Lobate deposits inside valleys, peripheral lobes and lateral ridges, as well as the energy required to surmount little slopes, overlap valley walls and reach the plateau, fit well with a viscous flow of fine material from the advance of a tsunami. Here, we interpret that these lobes are the remnant of an impact-induced flow with high energy that produced a large inundation subsequent to one or several tsunamis. In this context, thumbprint terrain would be related to the final stage evolution of the tsunami wave propagation, i.e. mud volcanoes that extruded water-mud mix material along the tsunami wave fronts. A wider coverage of high-resolution data would improve our understanding and reveal new crucial information in the ongoing debate of thumbprint terrain origin.

The presence (Parker et al., 1989, 1993; Head et al., 1998, 1999; Clifford and Parker, 2001; Carr and Head, 2003; Tanaka et al., 2003, 2005), and eventual freezing (Ivanov et al., 2014), of a former northern body of water, or a mud-ocean as Jöns (1987) proposed, provides the geological context for thumbprint terrain as mud volcanoes related to a tsunami event. In addition, crater counting showed that lobate TT unit is Early Amazonian; $2.8 \pm 0.2$ Gyr according to Hartmann 2004-iteration (Fig. S4 supplementary files). This crater counting analysis is concordant to a crater-retention age of 2.9 Gyr, proposed by Costard et al., 2017 for the same area, and to other previous literature (Hiesinger et al. 2009) which corresponds to an Early Amazonian/Late Hesperian ocean, in agreement with Parker et al., 1993. The Late Hesperian is also the timing of peak outflow channel activity, and thus is consistent with the presence of a transient northern ocean $\sim 3 \mathrm{Ga}$.

Giving morphologies and scales, fully thermal inertia and albedo values compliance, multiple impact craters possibility fitting numerical simulations, the occurrence of TT with lobes, their congruous alignments with inferred lobes direction and in favour of a general geological context, we herein mainly support the tsunami-driven mud-volcanoes hypothesis rather than others mentioned above.

\section{Acknowledgements}

This research was partially conducted and supported by the Programme National de Planétologie (PNP) of Institut National des Sciences de I'Univers (CNRS-INSU), the Centre National d'Etudes Spatiales (CNES). The EXOMHYDR project within the TEAM 
programme of the Foundation for Polish Science co-financed by the European Union under the European Regional Development Fund (contract TEAM/2016-3/20). Our gratitude also goes to Dr. Jakub Ciazela for contribution in the ATI method and supported us actively and made it possible to conclude the study.

\section{References}

Andreassen, K., Hubbard, A., Winsborrow, M., Patton, H., Vadakkepuliyambatta, S., Plaza-Faverola, A., ... \& Mienert, J., 2017. Massive blow-out craters formed by hydrate-controlled methane expulsion from the Arctic seafloor. Science, 356(6341), 948-953.

Baker, V. R., Strom, R. G., Gulick, V. C., Kargel, J. S., Komatsu, G., Kale, V. S., 1991. Ancient Oceans, Ice Sheets and the Hydrological Cycle on Mars. Nature. 352, 589-594.

Bamberg, M., Asche, H., Jaumann, R., 2013. Additional tools for surface analysis in ArcGIS. EPSC Abstracts Vol. 8, EPSC2013-435, 2013. European Planetary Science Congress 2013.

Bryant, E. A., 2001. Tsunami: The Underrated Hazard, pp. 320, Cambridge Univ. Press, Cambridge.

Buczkowski, D. L., Cooke, M. L., 2004. Formation of double-ring circular grabens due to volumetric compaction over buried impact craters: Implications for thickness and nature of cover material in Utopia Planitia, Mars. Journal of Geophysical Research: Planets. 109.

Buczkowski, D. L., Seelos, K. D., Cooke, M. L., 2012. Giant polygons and circular graben in western Utopia basin, Mars: Exploring possible formation mechanisms. Journal of Geophysical ResearchPlanets. 117.

Catling, C., Leovy, C.B., Wood, S.E., Day, M.D., 2012. Does the Vastitas Borealis Formation contain oceanic or volcanic deposits?: Third Conference on Early Mars: Geologic, Hydrologic, and Climatic Evolution and the Implications for Life, 21-25 May 2012, Lake Tahoe, Nevada: LPI Contribution no. 1680 , abstract 7031.

Carr, M.H., 1979. Formation of martian flood features by release of water from confined aquifers. J. Geophys. Res. 84, 2995-3007.

Carr, M. H., 1986. Mars - a Water-Rich Planet. Icarus. 68, 187-216.

Carr, M. H., 1990. D/H on Mars Effects of Floods, Volcanism, Impacts, and Polar Processes. Icarus. 87, 210-227.

Carr, M.H., 1995. The Martian drainage system and the origin of valley networks and fretted channels. Journal of Geophysical Research: Planets, 100(E4), pp.7479-7507.

Carr, M. H., Head, J. W., 2003. Oceans on Mars: An assessment of the observational evidence and possible fate. Journal of Geophysical Research-Planets. 108.

Christensen, P. R., Jakosky, B. M., Kieffer, H. H., Malin, M. C., McSween, H. Y., Nealson, K., ... \& Ravine, M., 2004. The thermal emission imaging system (THEMIS) for the Mars 2001 Odyssey Mission. Space Science Reviews, 110(1-2), 85-130.

Citron, R., Manga, M. \& Hemingway, D., 2018. Timing of oceans on Mars from shoreline deformation. Nature 555, 643-646 doi:10.1038/nature26144

Clifford, S. M., Parker, T. J., 2001. The evolution of the Martian hydrosphere: Implications for the fate of a primordial ocean and the current state of the northern plains. Icarus. 154, 40-79.

Cooke, M., Islam, F., McGill, G., 2011. Basement controls on the scale of giant polygons in Utopia Planitia, Mars. Journal of Geophysical Research-Planets. 116. 
Costard, F., Séjourné, A., Lagain, A., Ormö, J., Rodriguez, J. A. P., Clifford, S., et al., 2019. The Lomonosov crater impact event: A possible mega-tsunami source on Mars. Journal of Geophysical Research: Planets, 124, 1840- 1851. https://doi.org/10.1029/2019JE006008.

Costard, F., Séjourné, A., Kelfoun, K., Clifford, S., Lavigne, F., Di Pietro, I., Bouley, S., 2017. Modeling tsunami propagation and the emplacement of thumbprint terrain in an early Mars ocean, Journal of Geophysical Research-Planets. 122.

De Toffoli, B., Pozzobon, R., Massironi, M., Mazzarini, F., Conway, S., \& Cremonese, G., 2019. Surface Expressions of Subsurface Sediment Mobilization Rooted into a Gas Hydrate-Rich Cryosphere on Mars. Scientific reports, 9(1), 8603. doi:10.1038/s41598-019-45057-7.

Farmer, C. B., Doms, P. E., 1979. Global seasonal variation of water vapor on Mars and the implications for permafrost. J. Geophys. Res. 84, 2881-2888.

Farrand, W.H., Gaddis, L .R. , 2003. THEMIS Observations of Pitted Cones in Acidalia Planitia and Cydonia Mensae, Sixth International Conference on Mars, \#3094.

Farrand, W. H., Gaddis, L. R., Keszthelyi, L., 2005. Pitted cones and domes on Mars: Observations in Acidalia Planitia and Cydonia Mensae using MOC, THEMIS, and TES data. Journal of Geophysical Research-Planets. 110.

Fergason, R. L., Christensen, P. R., Kieffer, H. H., 2006. High-resolution thermal inertia derived from the Thermal Emission Imaging System (THEMIS): Thermal model and applications. Journal of Geophysical Research-Planets. 111.

Frey, J. V., Jarosewich, M., 1982. Subkilometer Martian volcanoes: Properties and possible terrestrial analogs, J. Geophys. Res., 87(B12),9867-9879, doi:10.1029/JB087iB12p09867.

Greeley, R., Guest, J.E., 1987. Geologic map of the eastern equatorial region of Mars, 1:15,000,000 scale. US Geological Survey Geol. Inv. Ser., Map I-1802-B.

Grizzaffi, P., Schultz, P. H., 1989. Isidis Basin - Site of Ancient Volatile-Rich Debris Layer. Icarus. 77, 358-381.

Hartmann, W.K. and Neukum, G., 2001. Cratering chronology and the evolution of Mars. In Chronology and evolution of Mars (pp. 165-194). Springer, Dordrecht.

Head, J. W., Hiesinger, H., Ivanov, M. A., Kreslavsky, M. A., Pratt, S., Thomson, B. J., 1999. Possible ancient oceans on Mars: Evidence from Mars Orbiter Laser Altimeter data. Science. 286, 21342137.

Head, J. W., et al., 1998. Oceans in the past history of Mars: Tests for their presence using Mars Orbiter Laser Altimeter (MOLA) data. Geophysical Research Letters. 25, 4401-4404.

Heipke, C., Oberstb, J., Albertze, J., Attwenger, M., P. Dorninger, P., E. Dorrer, Ewe, M., Gehrke, S., Gwinner, K., Hirschmüller, H., Kim, J.R., Kirk, R.L., Mayer, H., Muller, J.P., Rengarajan, R., Rentsch, M., Schmidt, R., Scholten, F., Shani, J., Spiegel, M., Wählisch, M., Neukum, G., \& the HRSC Co-Investigator Team (2007). Evaluating planetary digital terrain models-The HRSC DTM test, Planetary and Space Science, 55 (14), 2173-2191, doi.org/10.1016/j.pss.2007.07.006.

Hiesinger, H., Rohkamp, D., Sturm, S., Thiessen, F. and Reiss, D., 2009.Thumbprint Terrain in Isidis Planitia, Mars: Geology, Ages, Morphology, and Morphometry. In EGU General Assembly Conference Abstracts (Vol. 11, p. 7812).

Jaumann, R., Neukum, G., Behnke, T., Duxbury, T.C., Eichentopf, K., Flohrer, J., Gasselt, S.V., Giese, B., Gwinner, K., Hauber, E. and Hoffmann, H., 2007. The high-resolution stereo camera (HRSC) experiment on Mars Express: Instrument aspects and experiment conduct from interplanetary cruise through the nominal mission. Planetary and Space Science, 55(7-8), pp.928-952.

Jöns, H. P., 1987. Large fossil mud lakes or giant mud sheet floods in Syrtis Major (Isidis Planitia) and Mare Australe. Mars. Lunar. Planet. Sci. 18,470-471.

lijima, Y., Goto, K., Minoura, K., Komatsu, G. and Imamura, F., 2014. Hydrodynamics of impact-induced tsunami over the Martian ocean. Planetary and Space Science, 95, pp.33-44. 
Ivanov, M. A., Hiesinger, H., Erkeling, G., Reiss, D., 2014. Mud volcanism and morphology of impact craters in Utopia Planitia on Mars: Evidence for the ancient ocean. Icarus. 228, 121-140.

Ivanov, M. A., Hiesinger, H., Erkeling, G., Reiss, D., 2015. Evidence for large reservoirs of water/mud in Utopia and Acidalia Planitiae on Mars. Icarus. 248, 383-391.

Kargel, J. S., Baker, V. R., Begét, J. E., Lockwood, J. F., Péwé, T. L., Shaw, J. S., \& Strom, R. G., 1995. Evidence of ancient continental glaciation in the Martian northern plains. Journal of Geophysical Research: Planets, 100(E3), 5351-5368.

Kargel, J. S., Strom, R. G., 1992. Ancient Glaciation on Mars. Geology. 20, 3-7.

Kneissl, T., van Gasselt, S., \& Neukum, G., 2011. Map-projection-independent crater size-frequency determination in GIS environments-New software tool for ArcGIS. Planetary and Space Science, 59(11-12), 1243-1254.

Kholodov, V. N., 2002. Mud volcanoes, their distribution, regularities, and genesis: Communication 1. Mud volcanic provinces and morphology of mud volcanoes. Lithol. Miner. Resour., 27, 197-209.

Komatsu, G., Okubo, C. H., Wray, J. J., Ojha, L., Cardinale, M., Murana, A., ... \& Gallagher, R., 2016. Small edifice features in Chryse Planitia, Mars: assessment of a mud volcano hypothesis. Icarus, 268, 56-75.

Kreslavsky, M. A., Head, J. W., 2002. Fate of outflow channel effluents in the northern lowlands of Mars: The Vastitas Borealis Formation as a sublimation residue from frozen ponded bodies of water. Journal of Geophysical Research-Planets. 107.

Lachenbruch, A. H., 1994. Permafrost, the active layer, and changing climate. Washington, DC: US Geological Survey.

Lavigne, F., Paris, R., Grancher, D., Wassmer, P., Brunstein, D., Vautier, F., ... \& Gomez, C., 2009. Reconstruction of tsunami inland propagation on December 26, 2004 in Banda Aceh, Indonesia, through field investigations. Pure and Applied Geophysics, 166(1-2), 259-281.

Lockwood, J. F., Kargel, J. S., Strom, R. B., 1992. Thumbprint Terrain on the Northern Plains: A Glacial Hypothesis. Abstracts of the Lunar and Planetary Science Conference, volume 23, page 795.

Lucchitta, B. K., 1981 . Mars and Earth: Comparison of cold-climate features. Icarus, 45, 264-303, doi:10.1016/0019-1035(81)90035-X.

MacDonald, G. J., 1990. Role of methane clathrates in past and future climates. Climatic Change, 16(3), 247-281.

Mackay, J. R., 1973. The growth of pingos, western Arctic coast, Canada, Can. J. Earth Sci., 10, 9791004.

MacKay, J. R., 1998. Pingo growth and collapse, Tuktoyaktuk Peninsula area, western arctic coast, Canada: A long-term field study. Geogr. Phys. Quat., 52, 1- 53.

Malin, M. C., Bell, J. F., Cantor, B. A., Caplinger, M. A., Calvin, W. M., Clancy, R. T., ... \& Lee, S. W., 2007. Context camera investigation on board the Mars Reconnaissance Orbiter. Journal of Geophysical Research: Planets, 112(E5)..

Malin, M. C., Edgett, K. S., 2001. Mars Global Surveyor Mars Orbiter Camera: Interplanetary cruise through primary mission. Journal of Geophysical Research-Planets. 106, 23429-23570.

Mangold, N., Allemand, P., Duval, P., Geraud, Y., Thomas, P., 2002. Experimental and theoretical deformation of ice-rock mixtures: Implications on rheology and ice content of Martian permafrost. Planetary and Space Science. 50, 385-401.

Maslin, M., Owen, M., Betts, R., Day, S., Dunkley Jones, T., \& Ridgwell, A., 2010. Gas hydrates: past and future geohazard? Philosophical Transactions of the Royal Society A: Mathematical, Physical and Engineering Sciences, 368(1919), 2369-2393.

McEwen, A. S., Eliason, E. M., Bergstrom, J. W., Bridges, N. T., Hansen, C. J., Delamere, W. A., ... \& Kirk, R. L., 2007. Mars reconnaissance orbiter's high resolution imaging science experiment (HiRISE). Journal of Geophysical Research: Planets, 112(E5). 
Mcgill, G. E., Hills, L. S., 1992. Origin of Giant Martian Polygons. Journal of Geophysical ResearchPlanets. 97, 2633-2647.

McGowan, E. M., 2011. The Utopia/Isidis overlap: Possible conduit for mud volcanism on Mars. Icarus. $212,622-628$.

Miyakawa, K., Tokiwa, T., Murakami, H., 2013. The origin of muddy sand sediments associated with mud volcanism in the Horonobe area of northern Hokkaido, Japan. Geochemistry Geophysics Geosystems. 14, 4980-4988.

Neukum, G. and Jaumann, R., 2004. HRSC: the High Resolution Stereo Camera of Mars Express, ESA SP-1240, September 2004.

Neukum G. 1983. Meteorite bombardment and dating of planetary surfaces. Translation of: Meteoriten bombardement und Datierung planetarer Oberfl€achen, Tenure Thesis, Ludwig-Maximilians University, Munich, Germany, NASA Technical Memorandum TM-77558, 1-186.

Oehler, D. Z., Allen, C. C., 2010. Evidence for pervasive mud volcanism in Acidalia Planitia, Mars. Icarus. 208, 636-657.

Parker, T. J., Gorsline, D. S., Saunders, R. S., Pieri, D. C., Schneeberger, D. M., 1993. Coastal Geomorphology of the Martian Northern Plains. Journal of Geophysical Research-Planets. 98, 11061-11078.

Parker, T. J., Saunders, R. S., Schneeberger, D. M., 1989. Transitional Morphology in West Deuteronilus Mensae, Mars - Implications for Modification of the Lowland Upland Boundary. Icarus. 82, 111-145.

Paris, R., Wassmer, P., Sartohadi, J., Lavigne, F., Barthomeuf, B., Desgages, E., ... \& Gomez, C., 2009. Tsunamis as geomorphic crises: lessons from the December 26, 2004 tsunami in Lhok Nga, west Banda Aceh (Sumatra, Indonesia). Geomorphology, 104(1-2), 59-72.

Perron, J. T., Mitrovica, J. X., Manga, M., Matsuyama, I., \& Richards, M. A., 2007. Evidence for an ancient martian ocean in the topography of deformed shorelines. Nature, 447(7146), 840-843.

Platz T., Michael G. G., Tanaka K. L., Skinner J. A. Jr., , Kneissl T., and Fortezzo C. M. 2013. Craterbased dating of geological units on Mars: Methods and application for the new global geological map. Icarus 225:806-827.

Rossbacher, L.A., Judson, S. , 1981. Ground ice on Mars: Inventory, distribution, and resulting landforms. Icarus, 45(1), 39-59, doi:10.1016/0019-1035(81)90005-1.

Rodriguez, J.A.P., Faire, A.G., Tanaka, K.L., Zarroca, M., Linares, R., Platz, T., Komatsu, G., Miyamoto, H., Kargel, J.S., Yan, J., Gulick, V., Higuchi, K., Baker, V.R., Glines, N, 2016. Tsunami waves extensively resurfaced the shorelines of an early Martian ocean. Scientific Reports, 6, 25106-1788.

Rodriguez, J.A.P., Thomas Platz, Virginia Gulick, Victor R. Baker, Alberto G. Fairén, Jeffrey Kargel, Jianguo Yan, Hideaki Miyamoto, Natalie Glines, 2015. Did the martian outflow channels mostly form during the Amazonian Period?, 2015. Icarus, Volume 257, Pages 387-395, ISSN 0019-1035, https://doi.org/10.1016/j.icarus.2015.04.024.

Sabol, D. E., Gillespie, A. R., McDonald, E., and Danilina, I., 2006. Differential Thermal Inertia of Geological Surfaces. In J. A. Sobrino, ed., Second Recent Advances in Quantitative Remote Sensing, Publicacions de la Universitat de València,Spain, ISBN: 84-370-6533-X ; 978-84-3706533-5, 193-198.

Salvatore, M. R., Christensen, P. R., 2014. On the origin of the Vastitas Borealis Formation in Chryse and Acidalia Planitiae, Mars. Journal of Geophysical Research-Planets. 119, 2437-2456.

Scott, D. H., Underwood, J. R., 1991. Mottled Terrain - a Continuing Martian Enigma. Proceedings of Lunar and Planetary Science. 21, 627-634.

Scott, D. H., Dohm, J. M., Rice, J. W. Jr., 1995. Map of Mars showing channels and possible paleolake basins. USGS Misc. Inv. Ser. Map I-2461, scale 1:30,000,000.

Skinner, J.A., Tanaka, K.L. and Fergason, R., 2008. Evidence for and implications of liquefaction in the Vastitas Borealis Marginal Unit in southern Utopia Planitia, Mars. In Lunar and Planetary Science Conference (Vol. 39, p. 2418). 
Skinner, J.A. and Fergason, R.L., 2010. Contrasting Flow Events in Chryse and Acidalia Planitiae, Mars, as Determined Through Landform Mapping and Spatial Analyses. In AGU Fall Meeting Abstracts.

Smith, D. E., et al., 2001. Mars Orbiter Laser Altimeter: Experiment summary after the first year of global mapping of Mars. Journal of Geophysical Research-Planets. 106, 23689-23722.

Salese, F., G. Di Achille, A. Neesemann, G. G. Ori, and E. Hauber, 2016. Hydrological and sedimentary analyses of well-preserved paleo fluvial-paleolacustrine systems at Moa Valles, Mars, J. Geophys. Res. Planets, 121, 194-232, doi:10.1002/2015JE004891.

Serov, P., Vadakkepuliyambatta, S., Mienert, J., Patton, H., Portnov, A., Silyakova, A., ... \& Hubbard, A., 2017. Postglacial response of Arctic Ocean gas hydrates to climatic amelioration. Proceedings of the National Academy of Sciences, 114(24), 6215-6220.

Serov, P., Portnov, A., Mienert, J., Semenov, P., \& llatovskaya, P., 2015. Methane release from pingo-like features across the South Kara Sea shelf, an area of thawing offshore permafrost. Journal of Geophysical Research: Earth Surface, 120(8), 1515-1529.

Souček, O., Bourgeois, O., Pochat, S., \& Guidat, T., 2015. A 3 Ga old polythermal ice sheet in Isidis Planitia, Mars: Dynamics and thermal regime inferred from numerical modeling. Earth and Planetary Science Letters, 426, 176-190.Tanaka, K. L., 1997. Sedimentary history and mass flow structures of Chryse and Acidalia Planitiae, Mars. Journal of Geophysical Research-Planets. 102, 4131-4149

Squyres, S.W., 1978. Martian fretted terrain: Flow of erosional debris. Icarus, 34(3), pp.600-613..

Tanaka, K. L., Scott, D. H., 1987. Geologic map of the polar regions of Mars, 1:15,000,000 scale. US Geological Survey Geol. Inv. Ser., Map I-1802-C.

Tanaka, K. L., Skinner, J. A., Hare, T. M., Joyal, T., Wenker, A., 2003. Resurfacing history of the northern plains of Mars based on geologic mapping of Mars Global Surveyor data. Journal of Geophysical Research-Planets. 108.

Tanaka, K. L., Skinner, J. A., Hare, T. M., 2005. Geologic map of the Northern Plains of Mars. US Geological Survey Sci. Inv, Map 2888.

Tuckwell, G. W., Lonergan, L., Jolly, R. J. H., 2003. The control of stress history and flaw distribution on the evolution of polygonal fracture networks. Journal of Structural Geology. 25, 1241-1250.

Wentworth, C.K., 1922. A scale of grade and class terms for clastic sediments. The journal of geology, 30(5), pp.377-392.

Wohletz, K. M., Sheridan, M .F., 1983. Hydrovolcanic explosions II. Evolution of basaltic tuff rings and tuff cones, Am. J. Sci., 283, 385-413.

Wood, C. A., 1979. Monogenetic volcanoes of the terrestrial planets, Proc. Lunar Planet. Sci. Conf. 10th, 2815-2840.

Zuber, M. T., 2018. Oceans on Mars formed early. Nature 555.7698 (2018): 592-591. 